\title{
Spatiotemporal control of supramolecular polymerization and gelation of metal-organic polyhedra
}

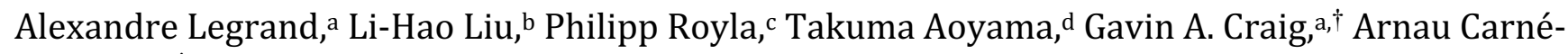 \\ Sánchez, ${ }^{\text {a, }}$ Kenji Urayama, ${ }^{\mathrm{d}}$ Jan J. Weigand, ${ }^{\mathrm{c}}$ Chia-Her Lin, ${ }^{\mathrm{b}, \#}$ Shuhei Furukawa ${ }^{\mathrm{a}, \mathrm{e}, *}$ \\ a Institute for Integrated Cell-Material Sciences, Kyoto University, Yoshida, Sakyo-ku, Kyoto 606-8501, Japan \\ b Department of Chemistry, Chung-Yuan Christian University, Chung Li, 32023 Taiwan \\ c Faculty of Chemistry and Food Chemistry, Technische Universität Dresden, 01062 Dresden, Germany \\ ${ }^{\mathrm{d}}$ Department of Macromolecular Science and Engineering, Kyoto Institute of Technology, Matsugasaki, Sakyo-ku, Kyoto \\ 606-8585, Japan
}

e Department of Synthetic Chemistry and Biological Chemistry, Graduate School of Engineering, Kyoto University, Katsura, Nishikyo-ku, Kyoto 615-8510, Japan

\begin{abstract}
In coordination-based supramolecular materials such as metallogels, simultaneous temporal and spatial control of their assembly remains challenging. Here, we demonstrate that the combination of light with acids as stimuli allows for the spatiotemporal control over the architectures, mechanical properties, and shape of porous soft materials based on metalorganic polyhedra (MOPs). First, we show that the formation of a colloidal gel network from a preformed kinetically trapped MOP solution can be triggered upon addition of trifluoroacetic acid (TFA), and that acid concentration determines the reaction kinetics. As determined by time-resolved dynamic light scattering, UV-vis absorption and ${ }^{1} \mathrm{H}$ NMR spectroscopies and rheology measurements, the consequences of the increase in acid concentration are (i) an increase in the cross-linking between MOPs; (ii) a growth in the size of the colloidal particles forming the gel network; (iii) an increase in the density of the colloidal network; and (iv) a decrease in the ductility and stiffness of the resulting gel. We then demonstrate that irradiation of a dispersed photoacid generator, pyranine, allows the spatiotemporal control of the gel formation by locally triggering the selfassembly process. Using this methodology, we show that the gel can be patterned into a desired shape. Such precise positioning of the assembled structures, combined with the stable and permanent porosity of MOPs, could allow their integration into devices for applications such as sensing, separation, catalysis, or drug release.
\end{abstract}

\section{Introduction}

In biological systems, self-assembly processes are often both temporally and spatially regulated. ${ }^{1,2}$ In fact, the kinetics of formation and the hierarchical assembly of the structures are responsive, and capable of adapting to changes in environment. ${ }^{3,4}$ Artificial supramolecular materials have been developed inspired by the sophisticated polymerizations found in nature..$^{5,}$ In such systems, the assembly of molecules into different architectures is controlled by the precise design of building blocks, encoded with specific functional groups to direct molecular recognition and interaction. $^{7}$

Often, the assembly pathways for artificial supramolecular materials are thermodynamically-driven; however, such pathways can offer a limited range of control over the resulting material properties and functions. In contrast, kinetic pathways can be used to obtain materials with increased structural and functional complexities because they offer temporal control (i.e. through reaction kinetics) ${ }^{8,9}$ and spatial control (i.e. through diffusion phenomena) ${ }^{10}$ of individual molecules, which can be manipulated either separately or simultaneously. Here, the challenge is to both generate chemical gradients, and regulate molecular interactions. ${ }^{11}$ One possible approach is to use microfluidics, which precisely controls flow rates and reactant diffusion. $.^{12} \mathrm{An}-$ other possible approach is the use of external physical or chemical stimuli, which can regulate the dynamic interactions between molecular building blocks. ${ }^{13}$ Light can be used to selectively and spatially trigger the formation of various supramolecular systems with defined shape and positioning.14-16 In addition, light can be converted into a chemical stimulus when it is used to irradiate a photoreceptor capable of releasing a proton (photoacid generator, PAG) or a base (photobase generator, PBG). ${ }^{17,} 18$ Thus, light could enable both temporal and spatial control of self-assembly. ${ }^{19}$

Metallogels have attracted interest because coordination chemistry offers a route to integrate metal ion-based properties (redox, optical, electronic, and magnetic) into soft materials that can be self-healing, elastic, and responsive to stimuli. ${ }^{20,21}$ In metallogels, the spatiotemporal control of the self-assembly process is limited because the metal ions that are part of the gel structure are also required to trigger the gelation, hindering the use of external stimuli. One strategy to circumvent this limitation is through the use of preformed metallacycles, metal-organic complexes, ${ }^{22,23}$ or even discrete molecular cages such as metal-organic polyhedra (MOPs). ${ }^{24,25}$ Recent advances with the latter have allowed porosity to be incorporated as a new property in the soft 
materials. ${ }^{26,27}$ MOPs, as building blocks, can be assembled into metallogels via a wide variety of intermolecular interactions such as electrostatic attraction, ${ }^{28,} 29$ dynamic-covalent bonds, ${ }^{30}$ coordination bonds, 31,32 or host-guest complexation, ${ }^{33,34}$ which can all be triggered in response to various stimuli. However, it is still a challenge to spatiotemporally control the reaction pathway, structures, and resulting properties of metallogels.

Here we show that the use of a photoacid can enable spatiotemporal control of the supramolecular polymerization of MOPs into porous colloidal gel networks with tunable architecture, mechanical properties, and shape. First, we demonstrate that acid can be used to induce the supramolecular polymerization reaction of monomeric MOP units (Figure 1a). Then, we demonstrate that irradiation of a pregelation mixture containing a PAG (pyranine) can spatially modulate the local concentration of acid and thus remotely trigger the self-assembly process and patterning of the solution into a gel of desired shape (Figure 1b).

\section{Results and discussion}

The separation of the MOP formation from their supramolecular polymerization into hierarchical structures enables the assembly process and resulting properties of the final material to be controlled without affecting the MOP unit. We recently demonstrated the multiscale self-assembly of a rhodium-based cuboctahedral MOP, $\left[\mathrm{Rh}_{2}\left(\mathrm{bdc}_{\mathrm{C}} \mathrm{C}_{12}\right)_{2}\right]_{12}$ $\left(\mathbf{C}_{12}\right.$ RhMOP; bdc- $\mathrm{C}_{12}=$ 5-dodecoxybenzene-1,3-dicarboxylate), into colloidal particles or porous gels through controlled assembly pathways with ditopic N-donor linkers. ${ }^{32}$ Stabilization of intermediate reactive species is a wellknown tool to direct the energy landscape of a chemical reaction towards a desired product. ${ }^{35,36}$ For the formation of a colloidal gel network from the rhodium-based MOP it is necessary to use 'coordination trapping' to first obtain a monomer, prior to supramolecular polymerization. This is achieved by simultaneous monodentate coordination of 12 equivalents of the ligand bix (bix: 1,4-bis(imidazole-1ylmethyl)benzene) to the twelve exohedral axial Rh sites of the MOP, yielding a kinetically trapped phase by isolation of (C12RhMOP)(bix)12 (Figure 1a). The mechanism of the supramolecular polymerization, triggered by heat, was previously studied by time-resolved dynamic light scattering (TR-DLS) ${ }^{37}$ and reported as following: first, the removal of monodentate bix from the kinetically isolated MOPs creates a coordinatively vacant site and initiates self-assembly among neighboring MOPs through the linking of ditopic bix to form nuclei of a few interconnected MOPs, followed by

(a)
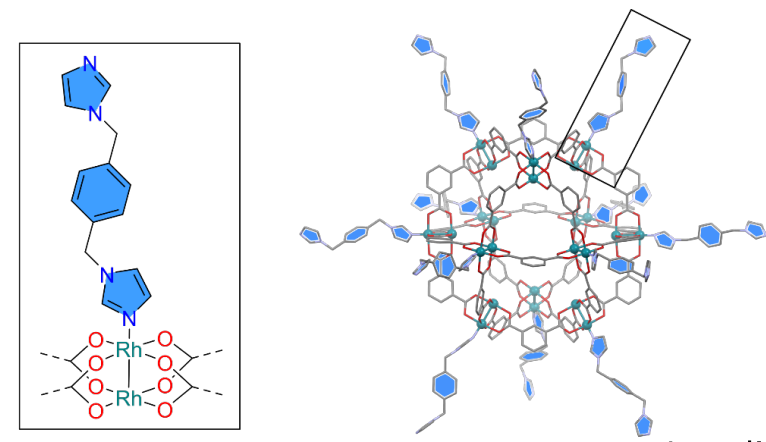

Localized

(b)
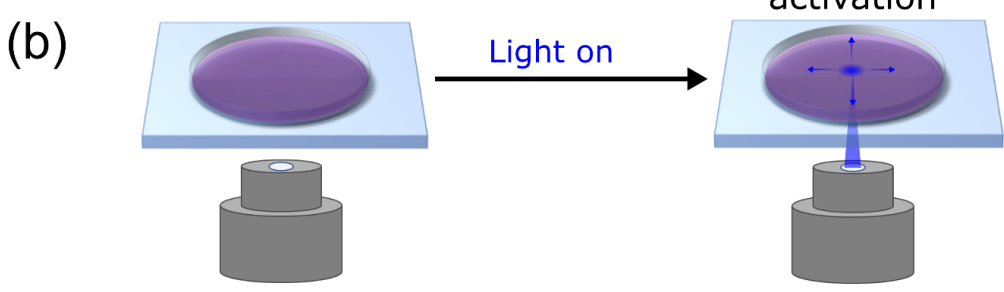

activation
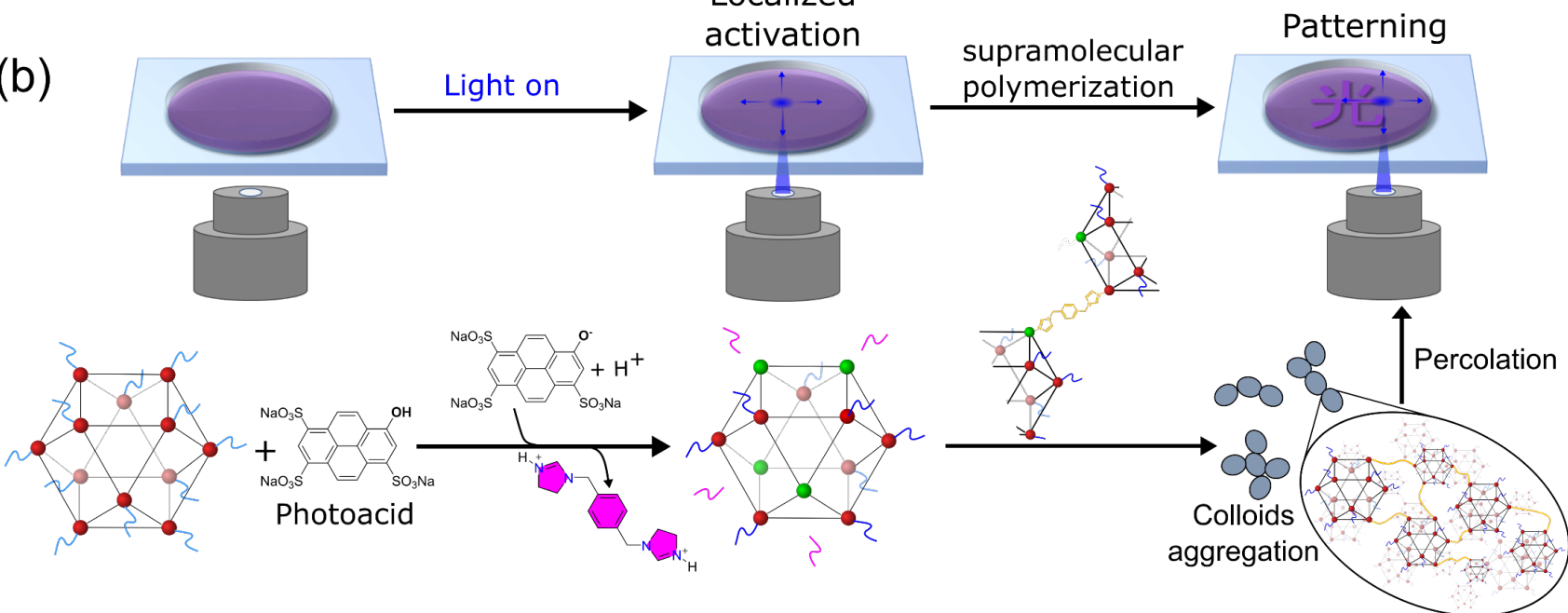

Figure 1. Strategy to achieve temporal and spatiotemporal control. (a) Schematic view of the molecular structure of the kinetically trapped MOP, ( $\left.\mathbf{C}_{\mathbf{1 2}} \mathbf{R h M O P ) ( b i x )}\right)_{12}$, where the twelve metal nodes of the cage are coordinated by bix molecules in a monodentate fashion (blue filled ring) with the corresponding simplified representation emphasizing the cuboctahedral shape of the cage (the alkyl chains are omitted for clarity). The addition of trifluoroacetic acid (TFA) triggers the supramolecular polymerization reaction and the formation of the porous colloidal gel network, $\left[\left(\mathbf{C}_{\mathbf{1 2}} \mathbf{R h M O P}\right)(\mathbf{b i x})_{\mathbf{x}}\right]_{\mathbf{n}}$. (b) Schematic representation of the photopatterning experiment using confocal laser scanning microscopy and the corresponding supramolecular polymerization reaction when irradiating the solution of the aged $\left(\mathbf{C}_{\mathbf{1 2}} \mathbf{R h M O P}\right)(\mathbf{b i x})_{\mathbf{1 2}}$ solution containing pyranine as photoacid. The use of TFA or pyranine lead, in both cases, to the protonation of bix molecules (pink filled ring) and the creation of labile metal sites (green), which initiates self-assembly among neighboring MOPs through the linking of ditopic bix (orange). 
their fusion into colloidal particles. At the critical gelation threshold, the colloids aggregate and percolate into an elastic colloidal network, yielding a supramolecular gel, 1 (Figure S1).

The Rh-based MOP is relatively stable to changes in $\mathrm{pH}$ thanks to the strong coordination bonds between the carboxylate ligands and the metal nodes. ${ }^{38}$ Therefore, we hypothesized that controlled addition of acid could be used to target the dissociation of the Rh-N coordination bond, providing an additional means of initiating the self-assembly of the MOPs as observed for biological or supramolecular systems. This is similar to the chemically induced bond cleavage that trigger the assembly of supramolecular hydrogels. ${ }^{39}$

Gel formation induced by trifluoroacetic acid (TFA). In an initial set of experiments, DMF solutions of (C C2RhMOP)(bix) $_{12}$ (1.38 mM) with 0.5, 1.0, 2.0, 6.0, 12.0 and 24.0 molar equivalents of TFA were prepared (1a-f) and the self-assembly process was monitored by TR-DLS. ${ }^{40}$ From these data, we can extract (i) the gelation threshold $\left(t_{\mathrm{g}}\right)^{41}$ and (ii) the characteristic correlation length $\left(\xi^{*}\right)^{42,43}$ of the colloidal network, yielding insight into the kinetics of the assembly process and the final architecture of the supramolecular gel, respectively. Figure 2 a shows the evolution of $t_{\mathrm{g}}$ as a function of the TFA added to solutions of the
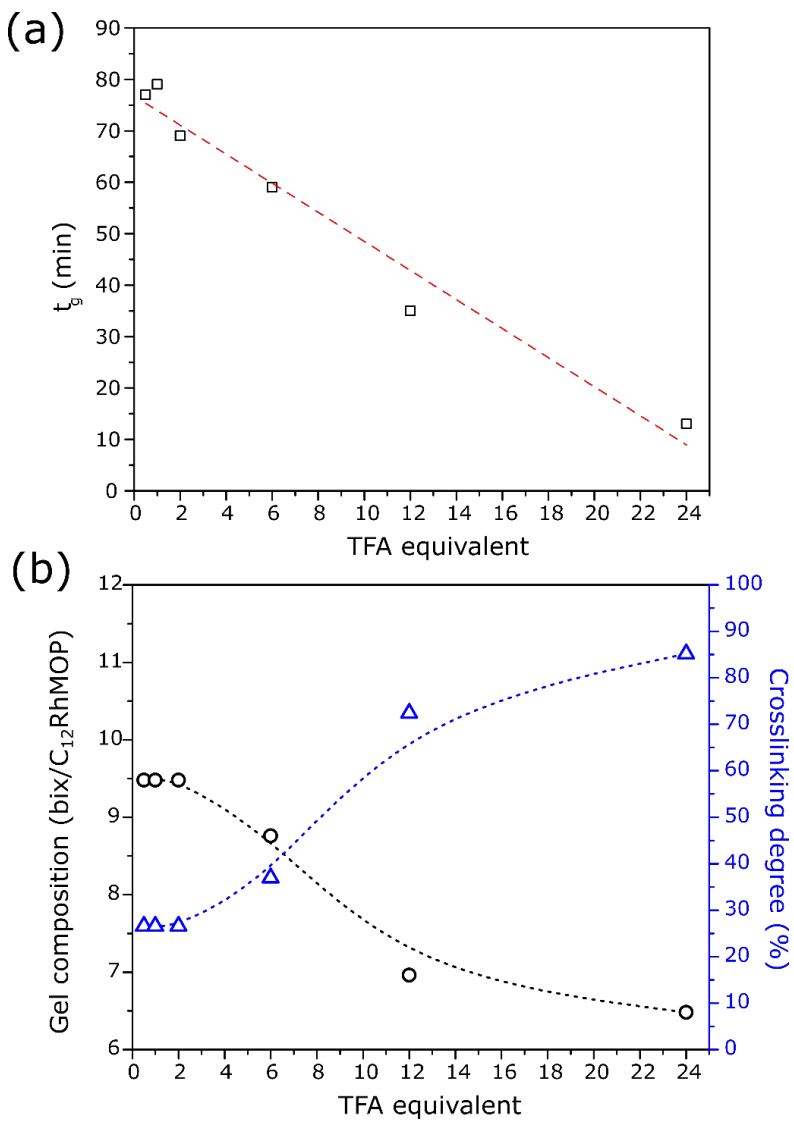

Figure 2. Variation of (a) the gelation threshold $t_{\mathrm{g}}$, (b) the gel composition and crosslinking degree as a function of TFA equivalent added to different DMF solutions of 1a-f prepared with a concentration of MOP of $1.38 \mathrm{mM}$. The gel composition was obtained from ${ }^{1} \mathrm{H}$ NMR spectra of digested samples in DMSO-d6/DCl. The dotted lines are a guide for the eyes. coordinatively trapped phase. Once polymerization begins, the MOPs assemble into colloidal particles, reflected by an increase in particle size during the course of the reaction (Fig. S2 top). The time taken for the sol-gel transition to occur was deduced from the plot of the scattering intensity as a function of time (Figure S2 bottom). For 1a ( 0.5 eq. of TFA), random fluctuations in the scattering intensity appear at 77 min, corresponding to the loss of particle mobility due to the formation of the colloidal network and the immobilization of the DMF solvent. As TFA content increases, the time to reach the onset of gelation decreases linearly, which is ascribed to the TFA protonating a greater number of bix molecules and therefore creating a higher number of vacant sites to be occupied by free imidazole moiety of monodentate bix attached to neighboring ( $\left.\mathbf{C}_{\mathbf{1 2}} \mathbf{R h M O P}\right)(\mathbf{b i x})_{12}$ molecules and accelerate the gel formation.

The proposed reaction mechanism is confirmed by ${ }^{1} \mathrm{H}$ NMR analysis of the digested gels (Figure S3). The gel composition $\left[\left(\mathbf{C}_{12} \mathbf{R h M O P}\right)(\mathbf{b i x})_{\mathbf{x}}\right]_{\boldsymbol{n}}$ is found to change with the molar equivalent of TFA added (Figure 2b, black). For 1a ( 0.5 eq. of TFA added), there are 9.5 bix molecules per MOP, of which 2.5 are crosslinked and 7 are monodentate. Meanwhile, for $\mathbf{1 f}$ ( 24.0 eq. of TFA) only 6.5 bix are present in the gel, of which 5.5 are crosslinked and 1 is monodentate. The change in the gel composition is associated with an increase in the degree of crosslinking between MOPs, which is tuned by the concentration of TFA (Figure $2 b$, blue; the crosslinking degree calculation is detailed in the SI). To support the assertion that bix is removed upon addition of TFA, a control experiment was performed using pyridine. First, the bare MOP $\mathbf{C}_{\mathbf{1 2}} \mathbf{R h M O P}$ in diethylformamide (DEF) was titrated with pyridine. UV-visible spectroscopy measurements showed that the initial MOP in DEF has a maximum absorbance $\left(\lambda_{\max }\right)$ at $592 \mathrm{~nm}$, which is shifted to $558 \mathrm{~nm}$ once 12 equivalents of pyridine were added to form the molecule $\mathbf{C}_{\mathbf{1 2}} \mathbf{R h M O P ( p y r )} \mathbf{1 2}$ (Figure S4). As a monodentate ligand, pyridine cannot link between MOPs upon removal. Stepwise addition of TFA from 1 to 192 molar equivalents led to a red shift of $\lambda_{\max }$ to $572 \mathrm{~nm}$, indicative of the pyridine dissociation from the axial position of $\mathrm{Rh}$ paddlewheel.

Gel architecture. Because the structure and bulk properties of supramolecular materials are the consequence of the self-assembly process, the change in the reaction kinetics observed when increasing TFA concentration should affect the architecture and mechanical properties of the gels. As mentioned above, TR-DLS can be used to extract the characteristic correlation length $\left(\xi^{*}\right.$; the fitting procedure is detailed in the SI). At the gelation threshold, $\xi^{*}$ is expected to be a measure of the average size of the colloidal clusters that have aggregated to form the gel network (Figure S5). In other words, this can also be approximated to the density of the gel network. ${ }^{44} \xi^{*}$ is observed to decrease exponentially with increasing TFA concentration from 0.5 to 24.0 equivalents (Figure 3a). This tendency means that the network of colloidal particles becomes denser with higher concentrations of TFA.

The gels 1a-f were converted to the corresponding aerogels 2a-f, after solvent exchange with acetone over three days, followed by drying with supercritical $\mathrm{CO}_{2}$. Field emission scanning electron microscopy (FE-SEM) images of the 
(a)

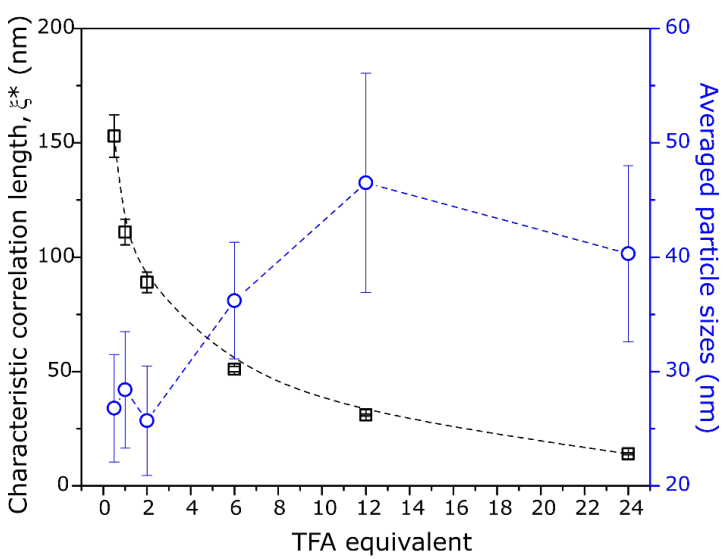

(b)

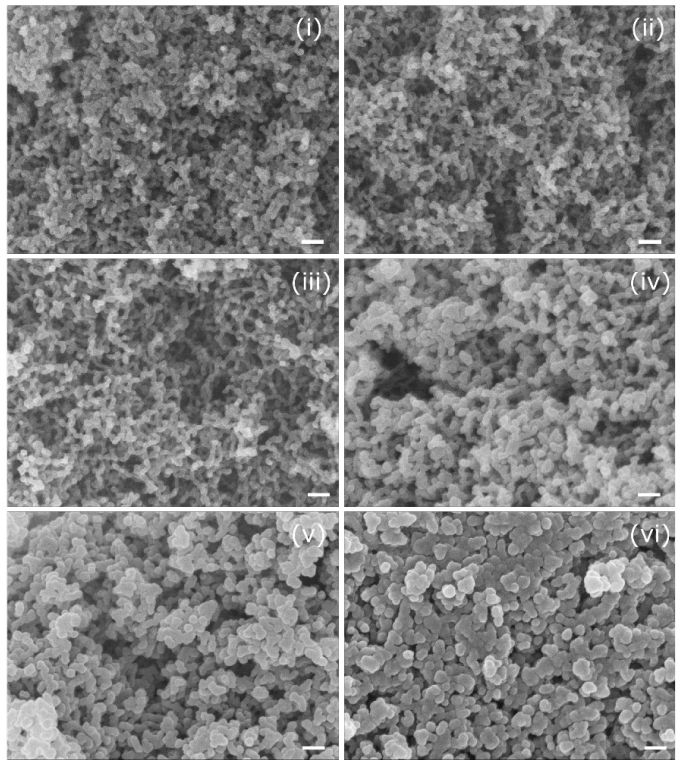

Figure 3. (a) Effect of the TFA equivalents added to different coordinated trapped phases on the characteristic correlation length. (b) FE-SEM images of the aerogels 2a-f prepared from lowest to highest TFA concentration. The scale bars are $100 \mathrm{~nm}$. The dotted lines are a guide for the eyes.

aerogels prepared with the lowest and highest TFA concentrations show distinct topological features (Figure $3 \mathrm{~b}$ and S9a). On the top left image of Figure 3b, 2a appears as a light network of aggregated colloidal particles. In contrast, a denser and almost fused network structure is found for $\mathbf{2 f}$ as expected from the observations made from the evolution of $\xi^{*}$ with TFA content (Figure 3b (vi)). Furthermore, the statistical analysis of the size distribution of colloidal particles revealed that the larger colloidal particles form with increasing TFA concentration $(26.8 \pm 4.7 \mathrm{~nm}$ for $\mathbf{2 a}$ and 40.3 $\pm 7.7 \mathrm{~nm}$ for $\mathbf{2 f}$, Figure 3a, blue; Figure S9b). This means that for samples $\mathbf{1 e}$ and $\mathbf{1 f}$, fewer colloidal particles are present in the system, which should induce a shrinkage of the gel volume compared to samples with lower TFA content. Indeed, photography of the samples 1e-f, prepared with 12 and 24 TFA equivalent, presented a decrease in the gel volume $\left(\sim 1.2 \mathrm{~cm}^{3}\right)$, while 1a-d maintained the initial volume of solution $\left(2.0 \mathrm{~cm}^{3}\right)$; 1 e-f showed the phase separation between the gel part on the bottom and the remaining solvent part on the top (Figure S10). These results are in striking contrast to the constant size of the colloidal particles $(\sim 30$ $\mathrm{nm}$ ) observed when studying the effect of the concentration of MOPs on the kinetics and architecture of the gel formation. ${ }^{37}$ In the present case, the change in the MOP monomer composition, as a result of the increase in concentration of TFA, leads to larger colloidal particles. The difference is explained by the nucleation and elongation model, in which separation of both steps is key to control the resulting particle size observed during supramolecular polymerization. ${ }^{32,45}$ Indeed, increasing the concentration of TFA results in fewer bix molecules coordinated per MOP $(\mathbf{1 f}=6.5 \mathbf{b i x}$ compared to $\mathbf{1 a}=9.5 \mathbf{b i x}$ ), leading to fewer nuclei formed and thus larger colloids. In addition, the rather compact colloidal clusters formed for samples 1e-f, as observed in SEM images and reflected by the decreased characteristic correlation length, are attributed to the increase of the volume fraction of particles due to the decrease of the gel volume.

Mechanical properties. The change in the chemical composition and/or architecture of various materials such as gels, ${ }^{46,47}$ polymer networks, ${ }^{48}$ and spider silks ${ }^{49}$ are known to have a direct effect on their mechanical properties. Therefore, measurements of the storage and loss Young's compression modulus, $\mathrm{E}^{\prime}$ and $\mathrm{E}^{\prime \prime}$, respectively, were carried out as a function of the oscillatory deformation frequency $\omega$, at a fixed strain amplitude (1\%) within the linear viscoelastic regime. Over the entire frequency range, these values are essentially constant and $\mathrm{E}^{\prime}$ is approximately one order of magnitude higher than $\mathrm{E}^{\prime \prime}$, confirming that the samples behave as elastic solids (Figure S11).

The large deformation behavior and the resistance to elastic deformation of the fully matured gel samples, 1a-f, were characterized by uniaxial compression tests. Stressstrain curves show four characteristic regimes (Figure 4a). First, a linear elastic regime is observed at low strain $(\varepsilon<$ $15 \%$ ), in which the materials deform elastically and can return to their original shape when the applied stress is removed. In this regime, the compressive elastic modulus (E) can be extracted from the slope of the linear fits. Then, a plateau regime occurs for $15<\varepsilon<40 \%$. The transition between the two regimes is characterized by the yield point, which indicates the limit between the elastic deformation and the beginning of plastic behavior. Figure $4 \mathrm{~b}$ shows the plot of the compressive elastic modulus (E) as a function of TFA equivalent added to the samples. When increasing the TFA content for the samples 1a-f, the elastic modulus, the yield strain and stress decrease (Figure $4 \mathrm{~b}$ inset), indicating a reduction in the resistance of the materials to permanent deformation..$^{50}$ Indeed, as for zirconia, alumina and Kaolin colloidal systems, it is expected that the yield point decreases as the particle size of the suspension increases. ${ }^{51,52}$ After the plateau regime ( $\varepsilon>40 \%$ ), strain hardening (or densification) is observed as the stress rises steeply. In this regime, the strengthening of the gel samples by plastic deformation occurs as a consequence of the colloidal gel networks rearrangement. Finally, above $\sim 80 \%$ strain, the stress drops suddenly, which is characteristic of the gel fracture. Samples with lower TFA content are more ductile and can undergo increased plastic deformation before breaking as seen from the maximum stress and strain reached for $\mathbf{1 a}$ compared to 1 ff $\left(1.8 \times 10^{5} \mathrm{~Pa}, 90.4 \%\right.$; and $3.8 \times 10^{4} \mathrm{~Pa}, 84.2 \%$, respectively). This is confirmed from the direct observation 


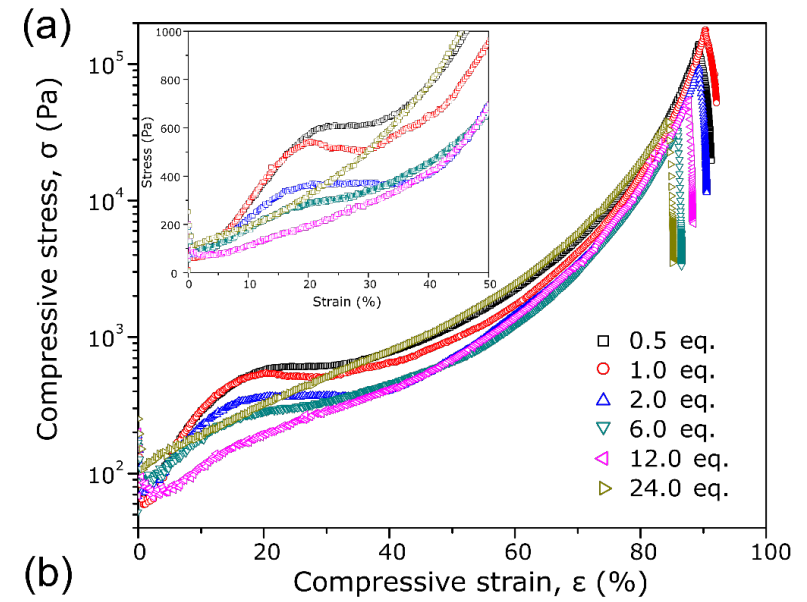

(b)

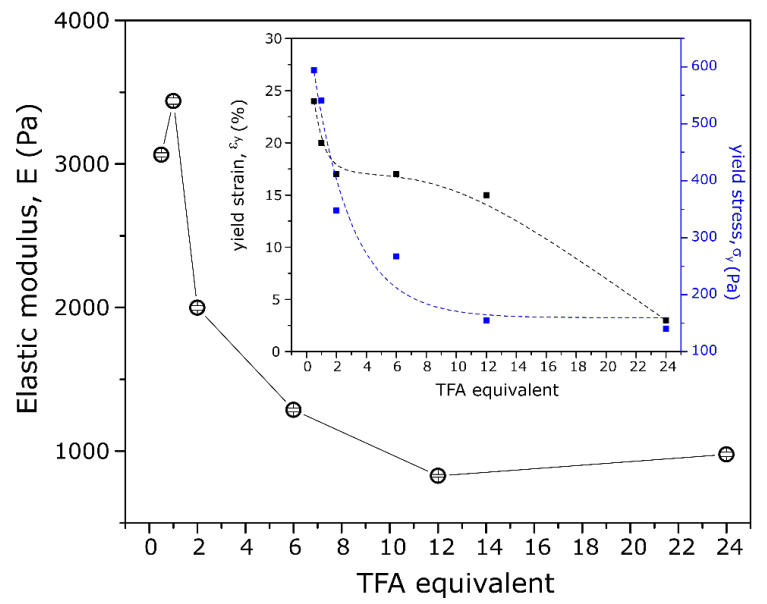

Figure 4. (a) Compression stress-strain curves and (b) elastic modulus, E, of the matured gels 1a-f showing the effect of TFA content on the mechanical response of the gels. The inset in Figure 4a offers a closer view of the low stressstrain region. The inset in Figure $4 \mathrm{~b}$ shows the evolution of the yield strain and stress as a function of TFA concentration. The solid and dotted lines are a guide for the eyes.

of the inverted gels, which shows the gels prepared with 12.0 and 24.0 eq. of TFA to be more brittle (Figure S12).

The rheology experiments showed that increasing the TFA content in the samples reduces the range of stress and strain where the gels behave elastically as shown by the decrease of the elastic modulus and the yield strength. These results can be attributed to a reduction in the bonding force between colloidal particles $(F)$. The force $F$ is correlated with the yield stress $\left(\sigma_{\mathrm{y}}\right)$ at which a colloidal network begins to break and the characteristic correlation length $\left(\xi^{*}\right)$ through: 53

$$
F \cong \frac{\sigma_{y} \xi^{* 3}}{a}
$$

where $a$ is the colloid size. The stress $\sigma_{\mathrm{y}}$ and $\xi^{*}$ decrease and $a$ increase upon increasing the TFA concentration. The equation above shows that all these variations result in a reduction in $F$. In addition, at the mesoscale, the connectivity between colloidal particles through monodentate bix at the surface of the colloids is hypothesized to be almost non-existent because the majority of the bix molecules in samples 1e and 1f are involved in crosslinking the MOPs as bidentate ligands as seen in Figure $2 \mathrm{~b}$. This explains why the gels become more brittle with increased TFA content.

$\mathrm{N}_{2}$ and $\mathrm{CO}_{2}$ adsorption experiments subsequent to activation at $120^{\circ} \mathrm{C}$ for $12 \mathrm{~h}$, performed on aerogels of $2 \mathrm{a}-\mathbf{f}$ at 77 $\mathrm{K}$ and $195 \mathrm{~K}$, respectively, show that the intrinsic porosity of the MOP cages is still accessible, indicating the preservation of the cage structure even after assembly into 3D colloidal networks (Figure S13). The maximum $\mathrm{CO}_{2}$ uptakes remain within a similar range of $30-35 \mathrm{~mol} \mathrm{CO}_{2} / \mathrm{mol}$ of $\mathrm{C}_{12}$ RhMOP at $P / P_{0}=0.95$ for all of the aerogels (Figure S13a). However, increasing the concentration of TFA causes a slight decrease in the $\mathrm{N}_{2}$ uptake (Figure S13b) in the meso/macroporous range $\left(0.2<\mathrm{P} / \mathrm{P}_{0}<1.0\right)$, attributed to the increased density of the aerogel networks, which leads to a reduction of macroporosity.

Photoacid generator and gel patterning. Having demonstrated that the addition of acid could be used to induce gelation, we sought to couple this behavior with irradiation, which would enable highly localized polymerization. Irradiation of the photoacid 8-hydroxypyren-1,3,6-trisulfonic acid (pyranine) has been shown to locally change $\mathrm{pH}$ due to a decrease in pKa from 7.3 to 1.4 , which can trigger self-assembly processes. ${ }^{54-56}$ The UV-visible spectrum of pyranine shows an absorption band in the UV region $\left(\lambda_{\max } \sim 400 \mathrm{~nm}\right)$ that, when irradiated, can induce the photodissociation of a proton, leading to the formation of the conjugated photobase (Figure S14a) ${ }^{57}$ Initial experiments with pyranine dispersed in the gelation mixture showed that concentrations of pyranine of 2 eq. induced gelation spontaneously, which was undesirable. In order to clearly implement a light-induced gelation process, a lower concentration of pyranine $(0.1 \mathrm{eq})$ was added to a solution of $1.38 \mathrm{mM}$ of ( $\mathbf{C}_{12}$ RhMOP)(bix) $)_{12}$ in a dark room, leading to gelation after $446 \mathrm{~min}$. In contrast, when irradiating the solution inside the DLS apparatus using a xenon light source with a $405 \mathrm{~nm}$ bandpass filter, random fluctuations in the scattering intensity appear after $124 \mathrm{~min}$, indicative of the sol-gel transition (Figure 5, red; Figure S14b). To demonstrate the direct effect of light on the kinetics of the supramolecular polymerization, the same experiment was carried out with a delay of $30 \mathrm{~min}$ between the start of the TR-DLS measurement and the commencement of in situ light irradiation (Figure 5, blue). The gelation threshold obtained from the scattering intensity (156 min) shows a delay of around 30 mins compared to the previous experiment, demonstrating that light can enhance the reaction kinetics via the excited state proton transfer of pyranine to the solvent and/or to the ditopic basic ligands in a similar mechanism to the one observed with TFA (Figure 5, black).

While the use of TFA to induce gelation will depend on diffusion of the acid throughout the matrix, the use of light offers a greater degree of spatial control. To investigate this possibility, confocal laser scanning microscope (CLSM) with a $405 \mathrm{~nm}$ laser was used to better control pattern formation. A lower amount of pyranine (0.033 eq.) was added to a solution of $1.1 \mathrm{mM}$ of $\left(\mathbf{C}_{\mathbf{1 2}} \mathbf{R h M O P}\right)(\mathbf{b i x})_{\mathbf{1 2}}$ in order to minimize ambient light triggering the gel formation in the CLSM experimental set-up. Without light irradiation, TR-DLS analysis of the solution shows that 32 hours are necessary for gelation (Figure 6b), indicating the long-term stability of the 


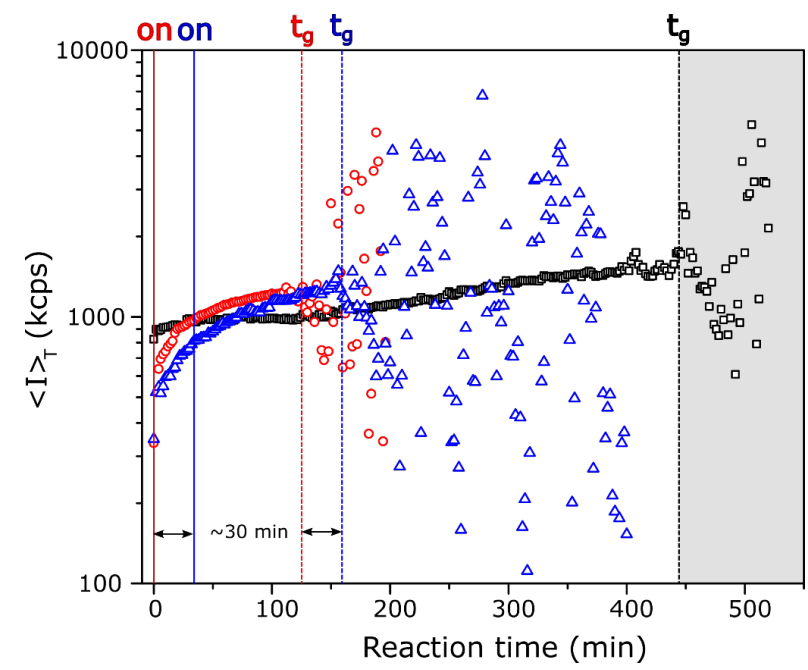

Figure 5. Evolution of the scattering intensity as a function of the reaction time of $1.38 \mathrm{mM}$ solutions of coordinated trapped MOP containing 0.1 eq. of pyranine (a) without irradiation (black squares), (b) with irradiation and (c) with irradiation started 30 min after the beginning of the DLS measurements. Xenon lamp with a $405 \mathrm{~nm}$ filter was used as light source.

solution. For this purpose, aliquots of the solution were collected at two different points of the reaction, after $60 \mathrm{~min}$ (Stage I) and $20 \mathrm{~h}$ (Stage II), and these fractions were irradiated under the CLSM with the $405 \mathrm{~nm}$ laser for $30 \mathrm{~min}$ to form a 'smiley' pattern. At Stage I, which corresponds to the nucleation step of the supramolecular polymerization reaction, the sample shows a low amount of gel formed and the pattern was barely visible (Figure 6a, left inset picture). In contrast, at Stage II, which corresponds to the colloid formation, clearly showed the patterned "smiley" gel (Figure $6 \mathrm{a}$, right insert picture). Therefore, the timing of the light irradiation during the reaction is important, and the solution must be aged until the fusion of nuclei of MOP network into colloidal particles $(\sim 20-30 \mathrm{~nm})$ before applying the light irradiation in order to obtain a spatially well-defined gel. To rule out the possibility that irradiation causes local heating which triggers gelation, a control sample of the coordination-trapped phase without pyranine was irradiated for 30 min; however, no gelation was observed (Figure S15a and b). Optimization of the experimental parameters of the confocal microscope showed the best performance to be obtained with a scan speed of $1 \mathrm{~mm} / 100 \mathrm{~s}$ and a magnification of 20x, in order to form sharp and continuous line (Figure 6c). With the finely tuned CLSM, we were able to pattern the gel to form the kanji "Hikari", which means light in Japanese (Figure 6d).

\section{Conclusion}

In porous materials like MOFs, physical and chemical stimuli are known to modulate the self-assembly process between organic ligands and metal ions, which affect the size, crystallinity, porosity, defect and surface chemistry of the extend network formed. ${ }^{58}$ Here we have demonstrated that the supramolecular polymerization reaction to fabricate porous soft materials can be chemically triggered by adding trifluoroacetic acid (TFA) in the solution of $\left(\mathbf{C}_{12} \mathbf{R h M O P}\right)(\mathbf{b i x})_{12}$, while changing the concentration of (a)

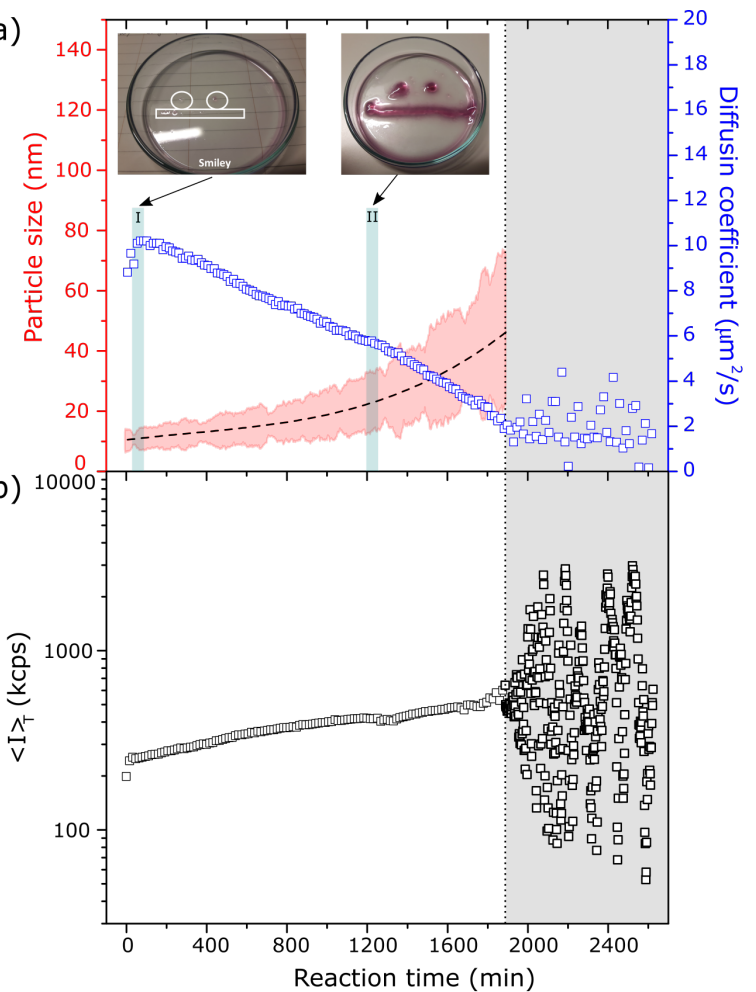

(c)

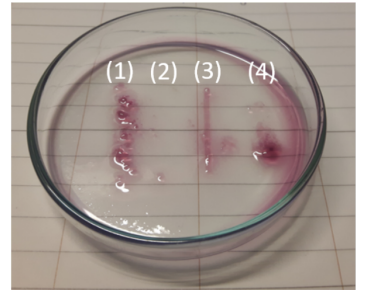

(d)

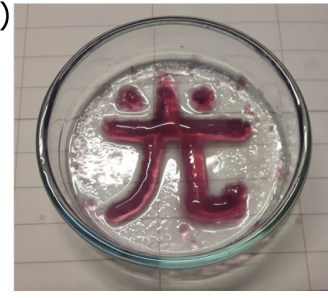

Figure 6. Evolution of (a) the particle size, diffusion coefficient and (b) scattering intensity as a function of time of the $1.1 \mathrm{mM}$ solutions of the coordinated trapped MOP containing 0.033 eq. of pyranine. The light irradiation of the sample at stage I ( $60 \mathrm{~min})$ and II $(20 \mathrm{~h})$ are represented by the blue area associated with the corresponding photography of the patterned gels. Photography of the gel formed after irradiating an aged solution of kinetically trapped phase containing 0.033 eq. pyranine with a confocal microscope showing (c) the optimization of the parameters of the confocal microscope using a scan speed and lens focal of (1) 1 $\mathrm{mm} / 100 \mathrm{~s}$ and $10 \mathrm{x}$ lens, (2) $1 \mathrm{~mm} / 12 \mathrm{~s}$ and $10 \mathrm{x}$ lens, (3) 1 $\mathrm{mm} / 100 \mathrm{~s}$ and $20 \mathrm{x}$ lens, and (4) $1 \mathrm{~mm} / 100 \mathrm{~s}$ and $100 \mathrm{x}$ lens. (d) Shaped gel in the Japanese kanji 'Hikari' formed after irradiating the solution with the optimized parameters of the confocal microscope. The petri dishes have a diameter of 6 in figure $6 \mathrm{a}$ and $\mathrm{c}$ and $4.5 \mathrm{~cm}$ in figure $6 \mathrm{~d}$.

TFA allows temporal control over the reaction kinetics. From the characterization techniques, we conclude that increase of TFA concentration leads to faster polymerization reaction due to an increased number of vacant coordination sites on MOPs, resulting in a faster nucleation and growth of colloids. In addition, the decreased number of bix per MOP with increasing TFA concentration leads to fewer nuclei formed and thus increased colloidal particle size. On the other hand, the macroscopic behavior of the gel is the result 
of the denser network, which is explained by the larger colloidal particles and the reduced volume of gel leading to the formation of more brittle gels as seen for $\mathbf{1 e - f .}$

While heat triggers gelation, it provides little control of the composition, architecture and mechanical properties of the MOP-based gel. Spatial control is also limited due to heat dissipation. In contrast, light offers the possibility to selectively and spatially trigger the chemical assembly/disassembly of various supramolecular systems. ${ }^{59-61}$ By dispersing a photo-acid in the gelation mixture, we were able to use light to remotely activate kinetically controlled self-assembly pathways, and at the same time precisely localize gelation of supramolecular polymers. This spatiotemporal control of assembly could enable the integration of MOP-based soft matter in devices for applications such as sensing, separation, and catalysis as observed for MOFs. ${ }^{62,63}$

\section{ASSOCIATED CONTENT}

\section{Supporting information}

The Supporting Information is available free of charge at on the ACS Publications website at DOI:.

Experimental methods, as well as synthetic procedure, TR-DLS data, ICF fitted curves, SEM images and size distribution, UVvis and ${ }^{1} \mathrm{H}$ NMR spectra, digital photo of the gels, storage and loss moduli spectra, $\mathrm{N}_{2}$ and $\mathrm{CO}_{2}$ gas adsorption.

\section{AUTHOR INFORMATION}

\section{Corresponding Author}

Shuhei Furukawa - Institute for Integrated Cell-Material Sciences, Kyoto University, Yoshida, Sakyo-ku, Kyoto 606-8501, Japan

Email: shuhei.furukawa@icems.kyoto-u.ac.jp

\section{Present Addresses}

† Present address: Department of Pure and Applied Chemistry, University of Strathclyde, Glasgow, UK

‡ Present address: Catalan Institute of Nanoscience and Nanotechnology (ICN2), CSIC and Barcelona Institute of Science and Technology, Bellaterra 08193, Barcelona, Spain

\# Present address: Department of Chemistry, National Taiwan Normal University, Wenshan District, Taipei, 11677, Taiwan.

\section{Notes}

The authors declare that they have no competing financial interests.

\section{ACKNOWLEDGMENT}

This study was supported by JSPS KAKENHI Grant Number 20K15366 (Wakate) for A.L. and 19H04575 (Coordination Asymmetry) and 18H01995 (Kiban B) for S.F. The authors thank the iCeMS Analysis Center for access to analytical instruments. Financial support for P.R. from the Erasmus+ program of the European Union is gratefully acknowledged. L.-H. L. and C.-H. L. acknowledge Chung-Yuan Christian University for the financial support.

\section{REFERENCES}

1. Blanchoin, L.; Boujemaa-Paterski, R.; Sykes, C.; Plastino, J., Actin Dynamics, Architecture, and Mechanics in Cell Motility. Physiol. Rev. 2014, 94 (1), 235-263.

2. Carlier, M. F., Role of Nucleotide Hydrolysis in the Dynamics of Actin Filaments and Microtubules. In Int. Rev. Cytol., Jeon, K. W.; Friedlander, M., Eds. Academic Press: 1989; Vol. 115, pp 139-170.

3. Janmey, P. A.; Hvidt, S.; Oster, G. F.; Lamb, J.; Stossel, T. P.; Hartwig, J. H., Effect of ATP on actin filament stiffness. Nature 1990, 347 (6288), 95-99.

4. $\quad$ Kovar, D. R.; Harris, E. S.; Mahaffy, R.; Higgs, H. N.; Pollard, T. D., Control of the Assembly of ATP- and ADP-Actin by Formins and Profilin. Cell 2006, 124 (2), 423-435.

5. Hendricks, M. P.; Sato, K.; Palmer, L. C.; Stupp, S. I., Supramolecular Assembly of Peptide Amphiphiles. Acc. Chem. Res. 2017, 50 (10), 2440-2448.

6. Dhiman, S.; Sarkar, A.; George, S. J., Bioinspired temporal supramolecular polymerization. RSC Advances 2018, 8 (34), 18913-18925.

7. Wang, J.; Liu, K.; Xing, R.; Yan, X., Peptide self-assembly: thermodynamics and kinetics. Chem. Soc. Rev. 2016, 45 (20), 5589 5604 .

$8 . \quad$ Ogi, S.; Sugiyasu, K.; Manna, S.; Samitsu, S.; Takeuchi, M., Living supramolecular polymerization realized through a biomimetic approach. Nat. Chem. 2014, 6 (3), 188-195.

9. Korevaar, P. A.; George, S. J.; Markvoort, A. J.; Smulders, M. M. J.; Hilbers, P. A. J.; Schenning, A. P. H. J.; De Greef, T. F. A.; Meijer, E. W., Pathway complexity in supramolecular polymerization. Nature 2012, 481 (7382), 492-496.

10. Yuan, C.; Ji, W.; Xing, R.; Li, J.; Gazit, E.; Yan, X., Hierarchically oriented organization in supramolecular peptide crystals. Nat. Rev. Chem. 2019, 3 (10), 567-588.

11. Zhan, J.; Cai, Y.; Ji, S.; He, S.; Cao, Y.; Ding, D.; Wang, L.; Yang, Z., Spatiotemporal Control of Supramolecular Self-Assembly and Function. ACS Appl. Mater. Interfaces 2017, 9 (11), 1001210018.

12. Sevim, S.; Sorrenti, A.; Franco, C.; Furukawa, S.; Pané, S.; deMello, A. J.; Puigmartí-Luis, J., Self-assembled materials and supramolecular chemistry within microfluidic environments: from common thermodynamic states to non-equilibrium structures. Chem. Soc. Rev. 2018, 47 (11), 3788-3803.

13. Sorrenti, A.; Leira-Iglesias, J.; Markvoort, A. J.; de Greef, T. F. A.; Hermans, T. M., Non-equilibrium supramolecular polymerization. Chem. Soc. Rev. 2017, 46 (18), 5476-5490.

14. Chivers, P. R. A.; Smith, D. K., Shaping and structuring supramolecular gels. Nat. Rev. Mater 2019, 4 (7), 463-478.

15. Draper, E. R.; Eden, E. G. B.; McDonald, T. O.; Adams, D. J., Spatially resolved multicomponent gels. Nat. Chem. 2015, 7 (10), 848-852.

16. Lee, H.-K.; Soukasene, S.; Jiang, H.; Zhang, S.; Feng, W.; Stupp, S. I., Light-induced self-assembly of nanofibers inside liposomes. Soft Matter 2008, 4 (5), 962-964.

17. Shirai, M.; Tsunooka, M., Photoacid and photobase generators: Chemistry and applications to polymeric materials. Prog. Polym. Sci. 1996, 21 (1), 1-45.

18. Zivic, N.; Kuroishi, P. K.; Dumur, F.; Gigmes, D.; Dove, A. P.; Sardon, H., Recent Advances and Challenges in the Design of Organic Photoacid and Photobase Generators for Polymerizations. Angew. Chem. Int. Ed. 2019, 58 (31), 10410-10422.

19. Maity, C.; Hendriksen, W. E.; van Esch, J. H.; Eelkema, R., Spatial Structuring of a Supramolecular Hydrogel by using a Visible-Light Triggered Catalyst. Angew. Chem. Int. Ed. 2015, 54 (3), 998-1001.

20. Shao, T.; Falcone, N.; Kraatz, H.-B., Supramolecular Peptide Gels: Influencing Properties by Metal Ion Coordination and Their Wide-Ranging Applications. ACS Omega 2020, 5 (3), 13121317.

21. Tam, A. Y.-Y.; Yam, V. W.-W., Recent advances in metallogels. Chem. Soc. Rev. 2013, 42 (4), 1540-1567. 
22. Wang, W.; Yang, H.-B., Linear neutral platinum-acetylide moiety: beyond the links. Chem. Commun. 2014, 50 (40), 51715186.

23. Sun, Y.; Chen, C.; Stang, P. J., Soft Materials with Diverse Suprastructures via the Self-Assembly of Metal-Organic Complexes. Acc. Chem. Res. 2019, 52 (3), 802-817.

24. Köberl, M.; Cokoja, M.; Herrmann, W. A.; Kühn, F. E., From molecules to materials: Molecular paddle-wheel synthons of macromolecules, cage compounds and metal-organic frameworks. Dalton Trans. 2011, 40 (26), 6834-6859.

25. Chakrabarty, R.; Mukherjee, P. S.; Stang, P. J., Supramolecular Coordination: Self-Assembly of Finite Two- and Three-Dimensional Ensembles. Chem. Rev. 2011, 111 (11), 68106918.

26. El-Sayed, E.-S. M.; Yuan, D., Metal-Organic Cages (MOCs): From Discrete to Cage-based Extended Architectures. Chem. Lett. 2019, 49 (1), 28-53.

27. Sutar, P.; Maji, T. K., Recent advances in coordinationdriven polymeric gel materials: design and applications. Dalton Trans. 2020, 49 (23), 7658-7672.

28. Wei, S.-C.; Pan, M.; Fan, Y.-Z.; Liu, H.; Zhang, J.; Su, C.-Y., Creating Coordination-Based Cavities in a Multiresponsive Supramolecular Gel. Chem. Eur. J. 2015, 21 (20), 7418-7427.

29. Ganta, S.; Chand, D. K., Multi-Stimuli-Responsive Metallogel Molded from a Pd2L4-Type Coordination Cage: Selective Removal of Anionic Dyes. Inorg. Chem. 2018, 57 (7), 3634-3645.

30. Uchida, J.; Yoshio, M.; Sato, S.; Yokoyama, H.; Fujita, M.; Kato, T., Self-Assembly of Giant Spherical Liquid-Crystalline Complexes and Formation of Nanostructured Dynamic Gels that Exhibit Self-Healing Properties. Angew. Chem. Int. Ed. 2017, 56 (45), 14085-14089.

31. Shao, L.; Hua, B.; Hu, X.; Stalla, D.; Kelley, S. P.; Atwood, J. L., Construction of Polymeric Metal-Organic Nanocapsule Networks via Supramolecular Coordination-Driven Self-Assembly. J. Am. Chem. Soc. 2020, 142 (16), 7270-7275.

32. Carné-Sánchez, A.; Craig, G. A.; Larpent, P.; Hirose, T.; Higuchi, M.; Kitagawa, S.; Matsuda, K.; Urayama, K.; Furukawa, S., Self-assembly of metal-organic polyhedra into supramolecular polymers with intrinsic microporosity. Nat. Commun. 2018, 9 (1), 2506.

33. Liu, Y.; Shi, B.; Wang, H.; Shangguan, L.; Li, Z.; Zhang, M.; Huang, F., Construction of Metallacage-Cored Supramolecular Gel by Hierarchical Self-Assembly of Metal Coordination and Pillar[5]arene-Based Host-Guest Recognition. Macromol. Rapid Commun. 2018, 39 (24), 1800655.

34. Lu, C.; Zhang, M.; Tang, D.; Yan, X.; Zhang, Z.; Zhou, Z.; Song, B.; Wang, H.; Li, X.; Yin, S.; Sepehrpour, H.; Stang, P. J., Fluorescent Metallacage-Core Supramolecular Polymer Gel Formed by Orthogonal Metal Coordination and Host-Guest Interactions. J. Am. Chem. Soc. 2018, 140 (24), 7674-7680.

35. Tantakitti, F.; Boekhoven, J.; Wang, X.; Kazantsev, R. V.; Yu, T.; Li, J.; Zhuang, E.; Zandi, R.; Ortony, J. H.; Newcomb, C. J.; Palmer, L. C.; Shekhawat, G. S.; de la Cruz, M. O.; Schatz, G. C.; Stupp, S. I., Energy landscapes and functions of supramolecular systems. Nat. Mater. 2016, 15 (4), 469-476.

36. Wehner, M.; Würthner, F., Supramolecular polymerization through kinetic pathway control and living chain growth. Nat. Rev. Chem. 2020, 4 (1), 38-53.

37. Legrand, A.; Craig, G. A.; Bonneau, M.; Minami, S.; Urayama, K.; Furukawa, S., Understanding the multiscale selfassembly of metal-organic polyhedra towards functionally graded porous gels. Chem. Sci. 2019, 10 (47), 10833-10842.

38. Mollick, S.; Fajal, S.; Mukherjee, S.; Ghosh, S. K., Stabilizing Metal-Organic Polyhedra (MOP): Issues and Strategies. Chem. Asian J. 2019, 14 (18), 3096-3108.

39. Ikeda, M., Stimuli-responsive supramolecular systems guided by chemical reactions. Polym. J. 2019, 51 (4), 371-380.
40. Mitsuhiro, S.; Tomohisa, N., Gel Formation Analyses by Dynamic Light Scattering. Bull. Chem. Soc. Jpn. 2002, 75 (4), 641659

41. Liu, R.; Gao, X.; Oppermann, W., Dynamic light scattering studies on random cross-linking of polystyrene in semi-dilute solution. Polymer 2006, 47 (26), 8488-8494.

42. Shibayama, M., Spatial inhomogeneity and dynamic fluctuations of polymer gels. Macromol. Chem. Phys. 1998, 199 (1), 1-30.

43. Asai, H.; Nishi, K.; Hiroi, T.; Fujii, K.; Sakai, T.; Shibayama, M., Gelation process of Tetra-PEG ion-gel investigated by timeresolved dynamic light scattering. Polymer 2013, 54 (3), 11601166.

44. Hule, R. A.; Nagarkar, R. P.; Altunbas, A.; Ramay, H. R.; Branco, M. C.; Schneider, J. P.; Pochan, D. J., Correlations between structure, material properties and bioproperties in self-assembled $\beta$-hairpin peptide hydrogels. Faraday Discuss. 2008, 139 (0), 251264

45. Kang, I.; Miyajima, D.; Mori, T.; Inoue, Y.; Itoh, Y.; Aida, $\mathrm{T}$., A rational strategy for the realization of chain-growth supramolecular polymerization. Science 2015, 347 (6222), 646651.

46. Haraguchi, K.; Farnworth, R.; Ohbayashi, A.; Takehisa, T. Compositional Effects on Mechanical Properties of Nanocomposite Hydrogels Composed of Poly(N,N-dimethylacrylamide) and Clay. Macromolecules 2003, 36 (15), 5732-5741.

47. Raub, C. B.; Unruh, J.; Suresh, V.; Krasieva, T.; Lindmo, T.; Gratton, E.; Tromberg, B. J.; George, S. C., Image Correlation Spectroscopy of Multiphoton Images Correlates with Collagen Mechanical Properties. Biophys. J. 2008, 94 (6), 2361-2373.

48. Urayama, K., Network Topology-Mechanical Properties Relationships of Model Elastomers. Polym. J. 2008, 40 (8), 669-678. 49. Du, N.; Liu, X. Y.; Narayanan, J.; Li, L.; Lim, M. L. M.; Li, D., Design of Superior Spider Silk: From Nanostructure to Mechanical Properties. Biophys. J. 2006, 91 (12), 4528-4535.

50. Diba, M.; Wang, H.; Kodger, T. E.; Parsa, S.; Leeuwenburgh, S. C. G., Highly Elastic and Self-Healing Composite Colloidal Gels. Adv. Mater. 2017, 29 (11), 1604672.

51. Kwade, A.; Schilde, C.; Burmeister, C.; Roth, M.; Lellig, P.; Auernhammer, G., Micromechanical properties of colloidal structures. AIP Conf. Proc. 2013, 1542 (1), 939-942.

52. Miller, K. T.; Melant, R. M.; Zukoski, C. F., Comparison of the Compressive Yield Response of Aggregated Suspensions: Pressure Filtration, Centrifugation, and Osmotic Consolidation. J. Am. Ceram. Soc. 1996, 79 (10), 2545-2556.

53. Uriev, N. B.; Ladyzhinsky, I. Y., Fractal models in rheology of colloidal gels. Colloids Surf., A 1996, 108 (1), 1-11.

54. Spies, C.; Finkler, B.; Acar, N.; Jung, G., Solvatochromism of pyranine-derived photoacids. PCCP 2013, 15 (45), 19893-19905. 55. $\quad$ Ma, R.; Wang, B.; Liu, X.; An, Y.; Li, Y.; He, Z.; Shi, L., Pyranine-Induced Micellization of Poly(ethylene glycol)-blockpoly(4-vinylpyridine) and pH-Triggered Release of Pyranine from the Complex Micelles. Langmuir 2007, 23 (14), 7498-7504.

56. Yucknovsky, A.; Mondal, S.; Burnstine-Townley, A.; Foqara, M.; Amdursky, N., Use of Photoacids and Photobases To Control Dynamic Self-Assembly of Gold Nanoparticles in Aqueous and Nonaqueous Solutions. Nano Lett. 2019, 19 (6), 3804-3810.

57. Liu, W.; Han, F.; Smith, C.; Fang, C., Ultrafast Conformational Dynamics of Pyranine during Excited State Proton Transfer in Aqueous Solution Revealed by Femtosecond Stimulated Raman Spectroscopy. J. Phys. Chem. B 2012, 116 (35), 10535-10550.

58. Forgan, R. S., Modulated self-assembly of metal-organic frameworks. Chem. Sci. 2020, 11 (18), 4546-4562.

59. Corrigan, N.; Yeow, J.; Judzewitsch, P.; Xu, J.; Boyer, C., Seeing the Light: Advancing Materials Chemistry through Photopolymerization. Angew. Chem. Int. Ed. 2019, 58 (16), 51705189. 
60. Manna, D.; Udayabhaskararao, T.; Zhao, H.; Klajn, R., Orthogonal Light-Induced Self-Assembly of Nanoparticles using Differently Substituted Azobenzenes. Angew. Chem. Int. Ed. 2015, 54 (42), 12394-12397.

61. Yang, X.; Zhang, G.; Zhang, D., Stimuli responsive gels based on low molecular weight gelators. J. Mater. Chem. 2012, 22 (1), 38-50.
62. Hirai, K.; Sada, K., Infrared laser writing of MOFs. Chem. Commun. 2017, 53 (38), 5275-5278.

63. Keitz, B. K.; Yu, C. J.; Long, J. R.; Ameloot, R., Lithographic Deposition of Patterned Metal-Organic Framework Coatings Using a Photobase Generator. Angew. Chem. Int. Ed. 2014, 53 (22), 55615565. 


\title{
Supporting information
}

\section{Spatiotemporal control of supramolecular polymerization and gelation of metal-organic polyhedra}

\author{
Alexandre Legrand, ${ }^{\text {a }}$ Li-Hao Liu, ${ }^{\text {b }}$ Philipp Royla, ${ }^{\mathrm{c}}$ Takuma Aoyama, ${ }^{\mathrm{d}}$ Gavin A. Craig, ${ }^{\mathrm{a}, \dagger}$ Arnau \\ Carné-Sánchez, ${ }^{\text {a, }}$ Kenji Urayama, d Jan J. Weigand, c Chia-Her Lin, ${ }^{\text {b, }}$ Shuhei Furukawa,e,* \\ a Institute for Integrated Cell-Material Sciences, Kyoto University, Yoshida, Sakyo-ku, Kyoto 606-8501, Japan \\ b Department of Chemistry, Chung-Yuan Christian University, Chung Li, 32023 Taiwan \\ c Chair of Inorganic Molecular Chemistry, Technische Universität Dresden, 01062 Dresden, Germany \\ d Department of Macromolecular Science and Engineering, Kyoto Institute of Technology, Matsugasaki, Sakyo- \\ ku, Kyoto 606-8585, Japan \\ e Department of Synthetic Chemistry and Biological Chemistry, Graduate School of Engineering, Kyoto University, \\ Katsura, Nishikyo-ku, Kyoto 615-8510, Japan
}




\section{Experimental \\ Materials}

All chemical reagents and solvents were purchased (Wako, Japan) and used without further purification. The detailed protocols for ligand and crosslinker synthesis can be found elsewhere. ${ }^{1}$

\section{Synthesis of $\mathrm{C}_{12} \mathrm{RhMOP}$}

The cuboctahedral MOP cage was synthesized as reported previously.2,3

\section{Synthesis of the kinetically trapped phase, $\left(\mathrm{C}_{12} \mathrm{RhMOP}\right)(\mathrm{bix})_{12}$}

The metastable state of the MOP was synthesized by solubilizing $\mathrm{C}_{12}$ RhMOP in $1.5 \mathrm{~mL}$ of DMF at $80^{\circ} \mathrm{C}$. The solution was added to $12 \mathrm{~mol}$. eq. of 1,4-bis(imidazole-1-ylmethyl)benzene (bix) in $1.5 \mathrm{~mL}$ at $80^{\circ} \mathrm{C}$ followed by a rapid cooling to room temperature in order to from isolated MOP molecules with the composition of $\left(\mathbf{C}_{12} \mathbf{R h M O P}\right)(\mathbf{b i x})_{12}$. The solutions of kinetically trapped MOP were prepared at a concentration of $1.38 \mathrm{mM}$ for TFA experiments and $1.1 \mathrm{mM}$ for photoacid experiments.

\section{Synthesis of supramolecular colloidal gel with TFA (1)}

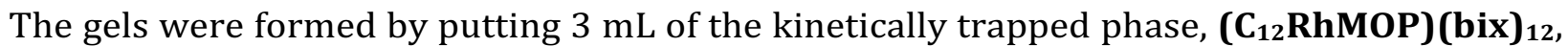
into a vial. Then, $0.5,1,2,6,12$ and 24 equivalents of TFA were added to the solution and quickly homogenized by shaking. The violet and transparent gels, 1a-f, are formed after few hours at room temperature due to the formation of the colloidal network and the immobilization of the DMF solvent through capillary forces and surface tension.

\section{Aerogel preparation (2)}

The gel samples were first washed with DMF and then exchanged with fresh acetone for 3 days. The supercritical $\mathrm{CO}_{2}$ drying process of the gels, to form the aerogels, was carried out on a SCLEAD-2BD autoclave (KISCO) using super-critical $\mathrm{CO}_{2}$ at $14 \mathrm{MPa}$ and $50{ }^{\circ} \mathrm{C}$ to give 2a, 2b, 2c, 2d, 2e, and $2 f$.

\section{Gels characterization}

The rheological measurements of the gels were made using a stress-controlled AR-G2 (TA Instruments, New Castle, DE, USA) rheometer. The measurements were conducted with a $1 \%$ strain amplitude that was well inside the linear regime.

Gelation was performed in a syringe during the same day prior rheological measurement in order to minimize solvent evaporation by adding $0.5,1,2,6,12$ and 24 equivalents of TFA into a $1.38 \mathrm{mM}$ solution of the kinetically trapped phase $\left(\mathbf{C}_{\mathbf{1 2}} \mathbf{R h M O P}\right)(\mathbf{b i x})_{12}$ to give the gels 1a-f during the course of few hours. After the reaction, the gel was removed from the syringe and the viscoelastic properties were directly measured.

The particle size, collective diffusion $(D)$, time-averaged autocorrelation function (ICF) and scattering intensity $\left(\langle I\rangle_{T}\right)$ were measured using time-resolved dynamic light scattering (TRDLS) performed on a Zetasizer Nano ZS instrument (Malvern Instruments, Malvern, UK). The light source was a HeNe laser working at $\lambda=633 \mathrm{~nm}$. The observations were made at the backscattering angle $\theta=173^{\circ}$. The time dependence of the particle size, $\langle I\rangle_{T}$ and ICF, during gelation process of freshly prepared solution $(1 \mathrm{~mL})$ of samples $1 \mathbf{1 a}, \mathbf{1 b}, \mathbf{1 c}, \mathbf{1 d}, \mathbf{1 e}, \mathbf{1 f}$ was evaluated at $25 \pm 0.5^{\circ} \mathrm{C}$ for few hours. Every $3 \mathrm{~min}$, the data of 10 independent measurements over $12 \mathrm{~s}$ were averaged. Note that the data thus obtained represent time-averaged characteristics where only one position of the sample is probed. The appearance of random variation in the scattering intensity is a clear indication of the gelation threshold, $\operatorname{tg}^{4}{ }^{4}$ At this 
stage, the diffusion becomes null rendering impossible for the DLS spectrometer to perform reliable measurement (Figure S2, gray region).

After gelation, the system becomes nonergodic and the ICF becomes dependent upon the sample position. However, when using long enough data collection time, a relative spatial homogeneity just after the gelation threshold can be assumed by considering the heterogeneities to be partially frozen-in and having still some mobility.

\section{Aerogels characterization}

$\mathrm{N}_{2}$ and $\mathrm{CO}_{2}$ gas sorption isotherms of the aerogels 2a-f were recorded on a BELSORP-mini volumetric adsorption instrument from BEL Japan Inc. at $77 \mathrm{~K}$ and $195 \mathrm{~K}$ respectively. Prior to gas sorption measurement, the samples were activated at $120^{\circ} \mathrm{C}$ for $12 \mathrm{~h}$.

Aerogel samples were observed using a field-emission scanning electron microscope (FESEM) with a JEOL Model JSM-7001F4 system operating at $10 \mathrm{kV}$ and $5 \mathrm{~mA}$ current.

1H-NMR spectra were recorded on a Bruker Biospin DRX-600 (600 MHz) spectrometer. For ${ }^{1} \mathrm{H}-\mathrm{NMR}$ analysis, $5 \mathrm{mg}$ of aerogel samples were digested in a mixture of DMSO-d6 (750 $\mu \mathrm{l}$ ) and $\mathrm{DCl}(50 \mu \mathrm{l})$. The mixture was heated at $100{ }^{\circ} \mathrm{C}$ overnight to obtain a yellow solution. The gel composition is determined from the ${ }^{1} \mathrm{H}$ NMR spectra of the digested sample by setting the integral of the protons to correspond to the one of the MOP linkers, which are then compared to the protons of the bix molecules (Figure S3). For all samples, the integral of the proton 1, corresponding to the - $\mathrm{CH} 3$ of the alkyl chain of the linker, is set to 3 and the value of the proton $\mathrm{e}$ of the bix molecule is chosen for the determine of the composition as follow $\mathrm{n}_{\text {bix }}=$ (integration value of proton e / 2) x 24

The crosslink degree was determined as follow:

$\operatorname{CLD}(\%)=($ number of bidentate bix $) /($ total amount of bix $) \times 100$

The total amount of bix is directly determined from the ${ }^{1} \mathrm{H}$ NMR spectra of the digested aerogels.

\section{Synthesis of supramolecular colloidal gel with pyranine}

In a dark room 0.1 eq. or 0.033 eq of a DMF solution of Pyranine (1.67 mM) was added to a solution of ( $\mathbf{C}_{12}$ RhMOP)(bix) $)_{12}(1.1 \mathrm{mM})$ and quickly vortexed.

For TR-DLS measurements, an Asahi Spectra Compact Xenon Light source MAX-303 with a $405 \mathrm{~nm}$ bandpass filter was used to irradiate in situ the solution of $\left(\mathbf{C}_{12} \mathbf{R h M O P}\right)(\mathbf{b i x})_{12}$ and 0.1 eq of pyranine with a cardboard surrounding to limit the exposure to other light sources.

Localized gelation experiments (patterning) were performed using the $405 \mathrm{~nm}$ Laser on an Olympus Confocal Laser Scanning Microscope FV1000. Spatial control was achieved by movement of the motorized microscope table with a minimum speed of $10 \mu \mathrm{m} . \mathrm{s}^{-1}$. 


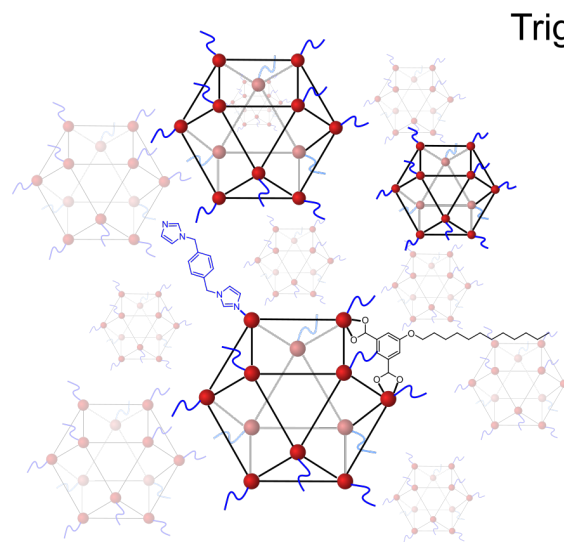

Solution of the coordinatively trapped phase

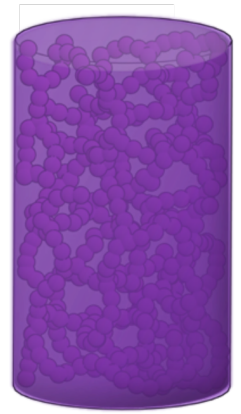

Colloidal gel network
Triggers of the supramolecular polymerization reaction
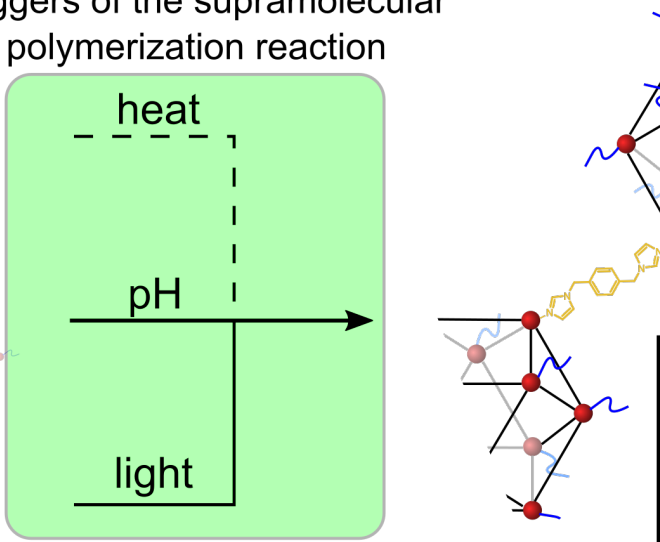

Nucleation and colloids formation

Figure S1. Mechanism of the supramolecular polymerization reaction leading to the formation of a colloidal gel network, 1 . The reaction can be triggered either by heating at $80^{\circ} \mathrm{C}$, changing the $\mathrm{pH}$, or irradiating with light in presence of a photoacid the solution of the coordinatively trapped phase, $\left(C_{12} \text { RhMOP)(bix) }\right)_{12}$. 

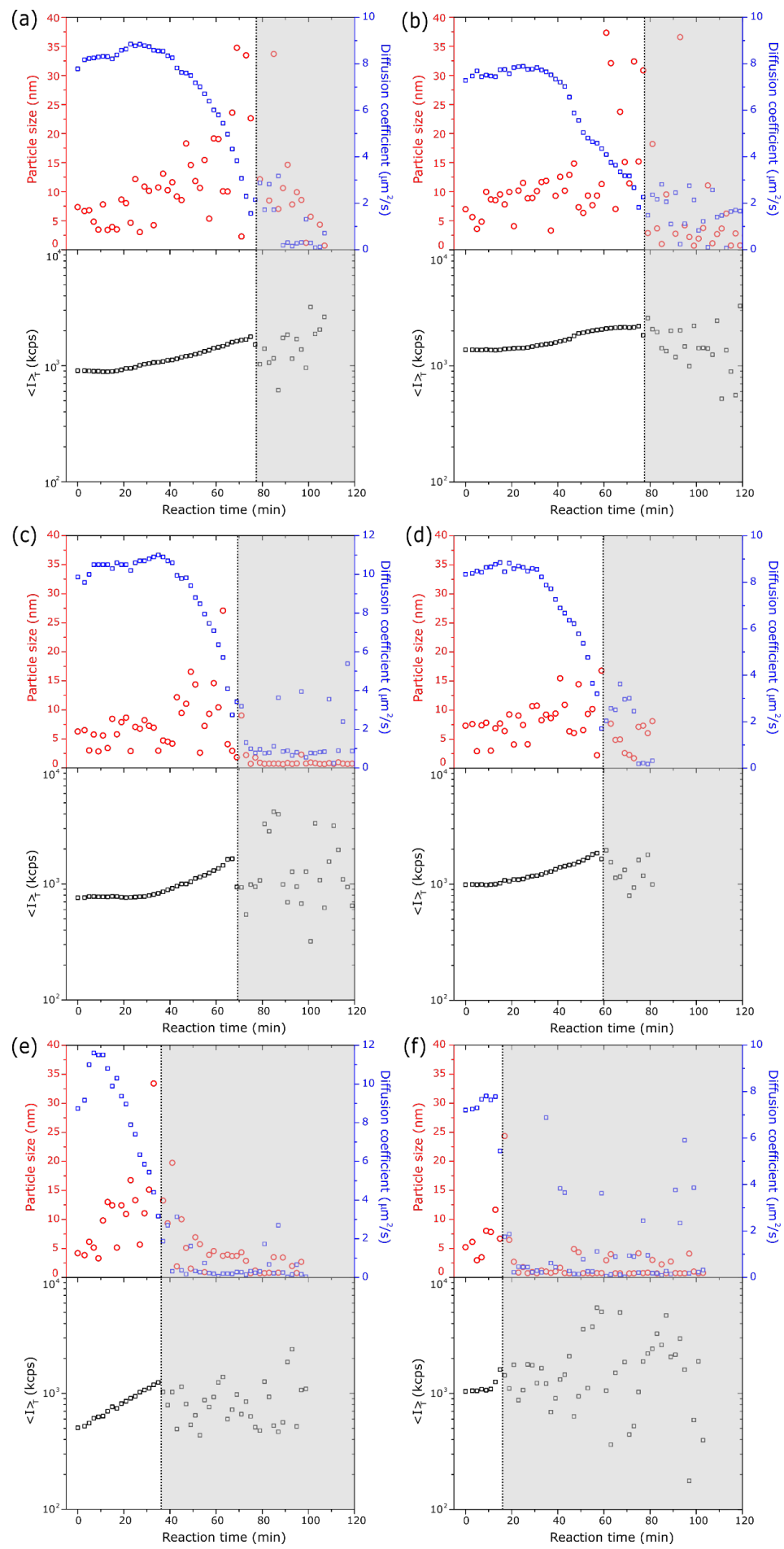

Figure S2. Gel formation of 1a-f followed by time-resolved dynamic light scattering technique (TR-DLS) at room temperature showing the evolution of the particle size (upper part) and scattering intensity $\langle 1\rangle_{\mathrm{T}}$ (lower part) as a function of the reaction time when a) 0.5, b) 1, c) 2, d) 6, e) 12, and f) 24 molar equivalent of TFA were added to a solution of the coordinatively trapped phase, $\left(\mathbf{C}_{12} \mathbf{R h M O P}\right)(\mathbf{b i x})_{12}$, in DMF (1.38 mM) 
(a)

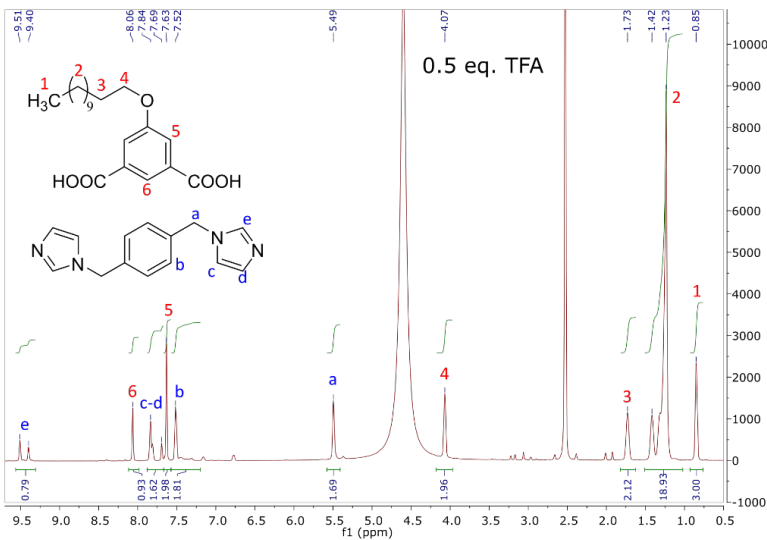

(b)

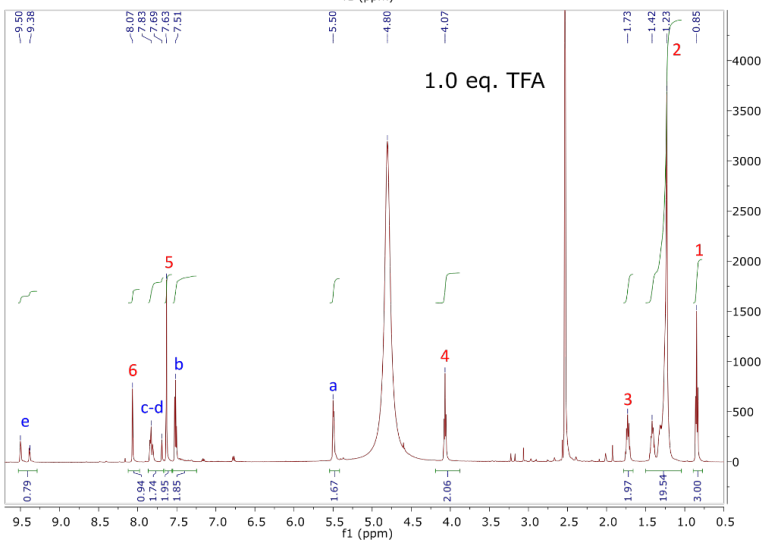

(d)

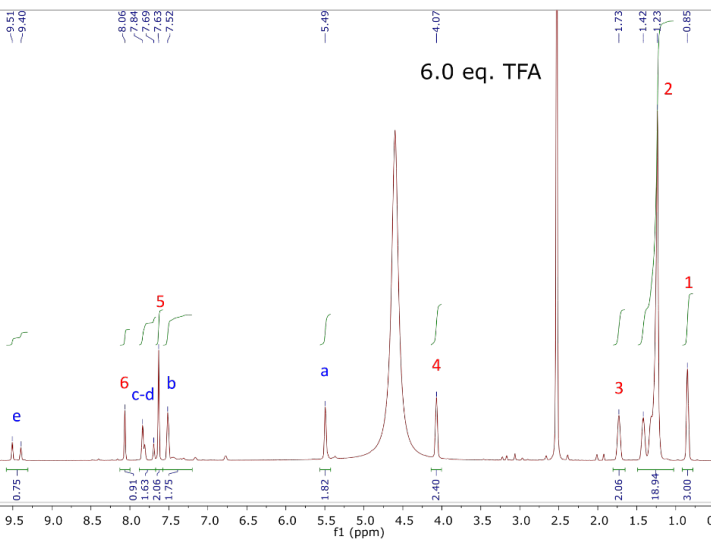

(e) 常
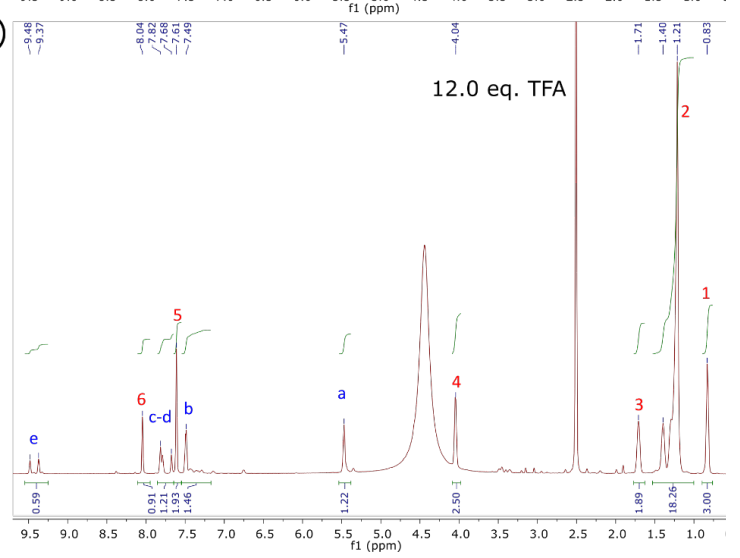

(c)
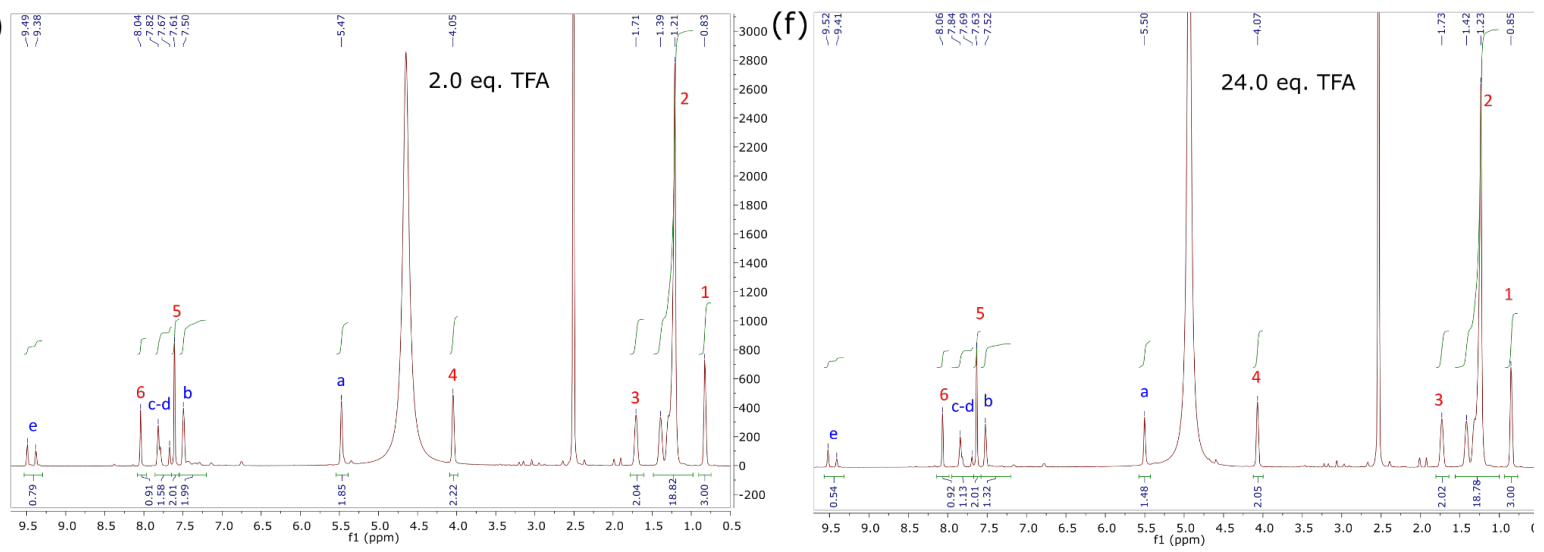

Figure S3. ${ }^{1} \mathrm{H}$ NMR of the digested samples 1 a-f in DMSO-d6/DCl prepared with a) 0.5, b) 1, c) 2, d) 6 , e) 12 , and f) 24 molar equivalents of TFA. 


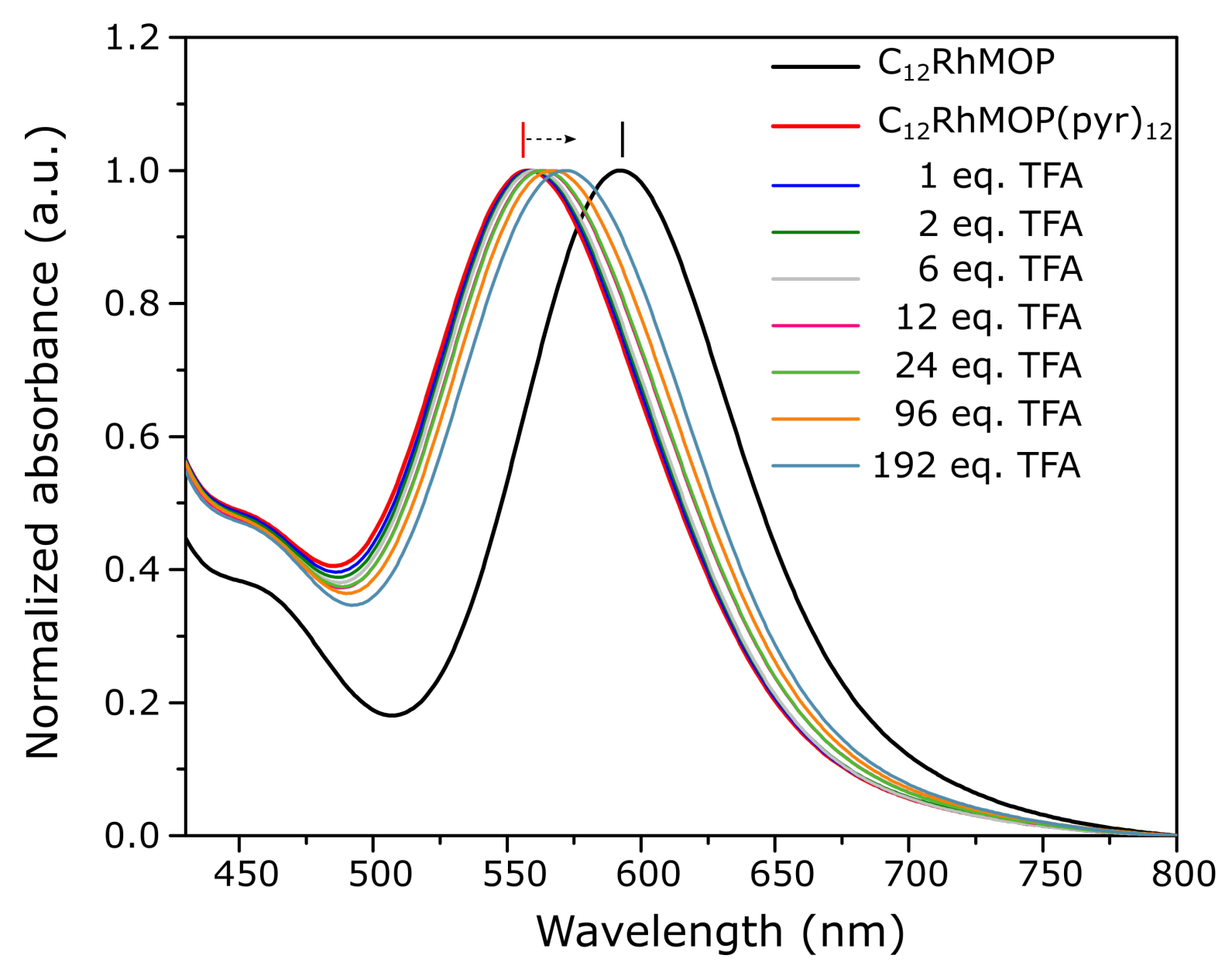

Figure S4. UV-visible spectra of the titration experiment of $\left(C_{12} R h M O P\right)(p y r)_{12}$ with 1 to 192 molar equivalents of TFA performed in diethylformamide (DEF). The bare $C_{12}$ RhMOP shows a maximum wavelength at $592 \mathrm{~nm}$ (black) which is shifted to $558 \mathrm{~nm}$ once fully coordinated with pyridine (red) to give $\left(\mathrm{C}_{12} \mathrm{RhMOP}\right)(\mathrm{pyr})_{12}$. 


\section{Theory background of dynamic light scattering (DLS)}

In DLS, the time-intensity correlation function (ICF) allows the time dependence of the diffusion of the scattering elements in the presence of noise to be extracted. The function represents the delay, in $\mu \mathrm{s}$, necessary for the diffusion speed of scattering particles to decay after interacting with incident light. In the solution state the ICF is best described by the sum of a single and stretched exponential functions:

$$
g^{(2)}(\tau)-1=\sigma_{1}^{2}\left\{A e^{\left(-\tau / \tau_{f}\right)}+(1-A) e^{-\left(\tau / \tau_{s}\right)^{\beta}}\right\}^{2}
$$

$\sigma_{1}^{2}$ is the initial amplitude of ICF with values close to the instrumental coherence factor (usually $\approx 1$ ). During the gelation process, the system tends towards nonergodicity resulting in a decrease in $\sigma_{1}^{2}$. A $(0<A<1)$ is the fraction of the collective diffusion mode. $\beta(0<\beta<1)$ is the stretched exponent and reflects the distribution of relaxation times of the slow mode. $\tau_{f}$ and $\tau_{s}$ are the characteristic relaxation times of the fast and slow modes respectively. $\tau_{f}$ is also called the gel mode and is related to the collective diffusion of local motions, $D_{c o l}$, by:

$$
\tau_{f}=1 /\left(q^{2} D_{c o l}\right)
$$

with $q$ the wave vector defined as:

$$
q=\frac{4 \pi r_{i}}{\lambda} \sin (\theta / 2)
$$

where $r_{i}$ is the refractive solvent index, $\lambda$ is the incident wavelength and $\theta$ is the angle at which the detector is placed. Here, the detector position is fixed at $173^{\circ}$ (backscattering mode) to reduce multiple scattering.

The collective diffusion $D_{c o l}$ is also related to the correlation length through the Stokes-Einstein equation:

$$
\xi=\frac{k_{B} T}{6 \pi \eta D_{c o l}}
$$

with $k_{B}$ the Boltzmann constant, $T$ the temperature and $\eta$ the viscosity of the solvent. In polymer gel systems, the correlation length corresponds to the distance between two cross-linked sites and is equivalent in our colloidal gel system to the distance between two branching units.

Insight into the colloidal network architecture can be obtained from the correlation length $\xi$, which reflects the evolution of the formation of colloidal clusters as a function of the reaction time. 5 In the solution phase, $\xi$ is obtained by fitting the intensity-correlation function (ICF) by a sum of single and stretched exponentials (Figure S6 and S7). ${ }^{4}$ Among the fitted parameters, the relaxation time of the fast components $\tau f$ is related to $\xi$ through the Stokes-Einstein equation. ${ }^{6}$ The values of $\xi$ is found to diverge just before the sol-gel transition (Figure S8) for all samples. Indeed, as the concentration of individual clusters increase, they begin to overlap and aggregate to form a continuous network. 


\section{TFA concentration}

\section{Colloidal}

sizes
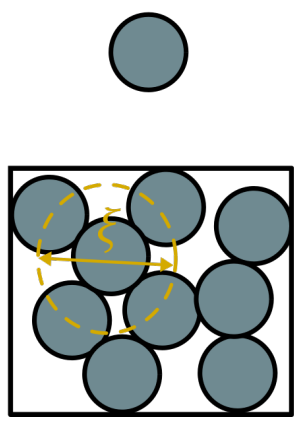

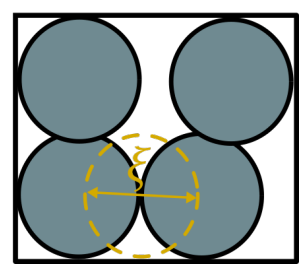

Figure S5. Schematic representation of the evolution of the size of colloidal particles, network density and the characteristic correlation length $\left(\xi^{*}\right)$ with increasing the concentration of TFA. 

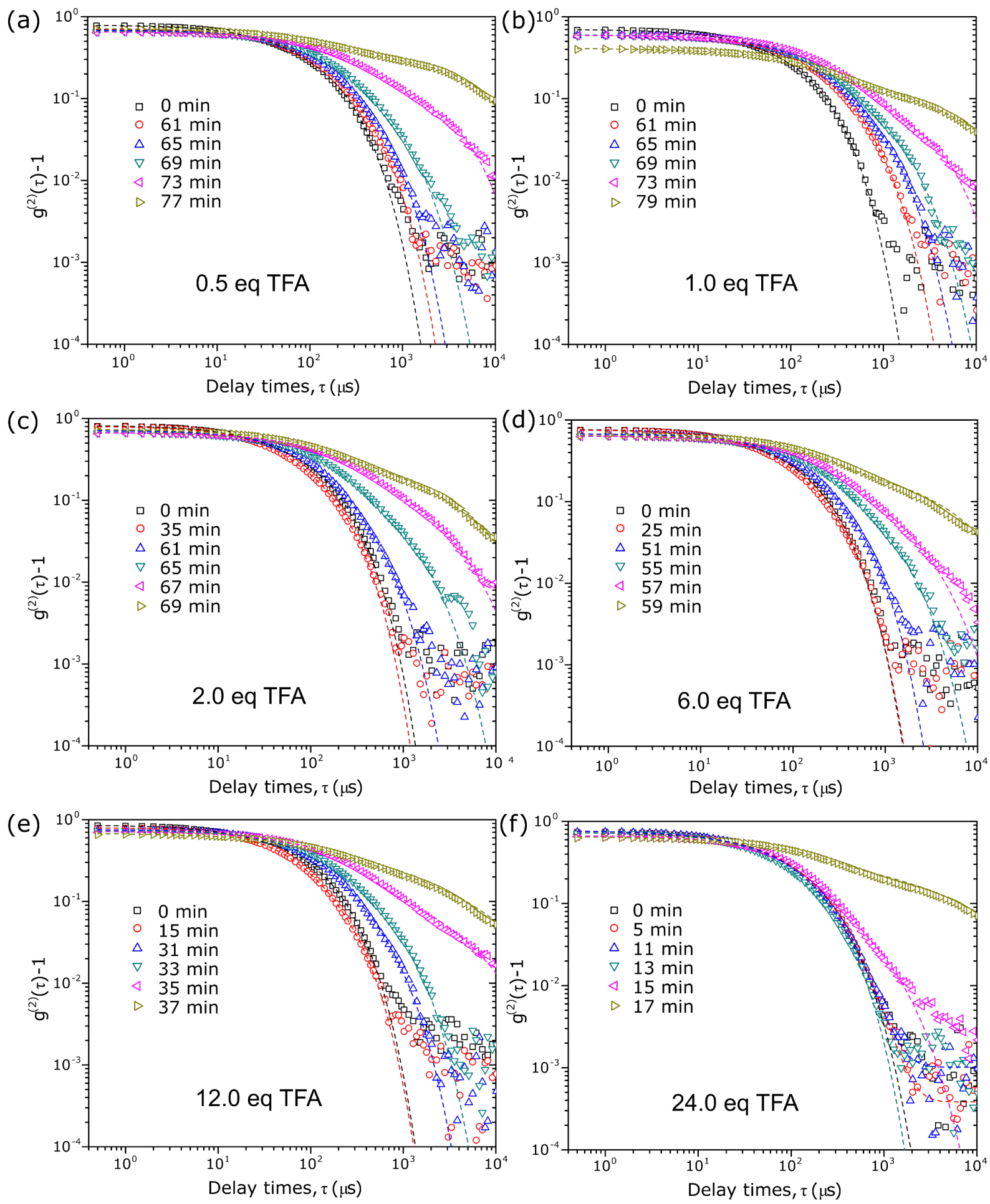

Figure S6. Evolution of the ICF of 1a-f as a function of the delay times for different reaction times of the solution of the kinetically trapped phase, $\left(\mathbf{C}_{12} \mathbf{R h M O P}\right)(\mathbf{b i x})_{12}$, prepared with (a) 0.5 eq, (b) 1.0 eq., (c) 2.0 eq, (d) 6.0 eq., (e) 12.0 eq and (f) 24.0 eq. of TFA at room temperature. The dotted lines represent the fit of ICF at different reaction times using equation 1. 

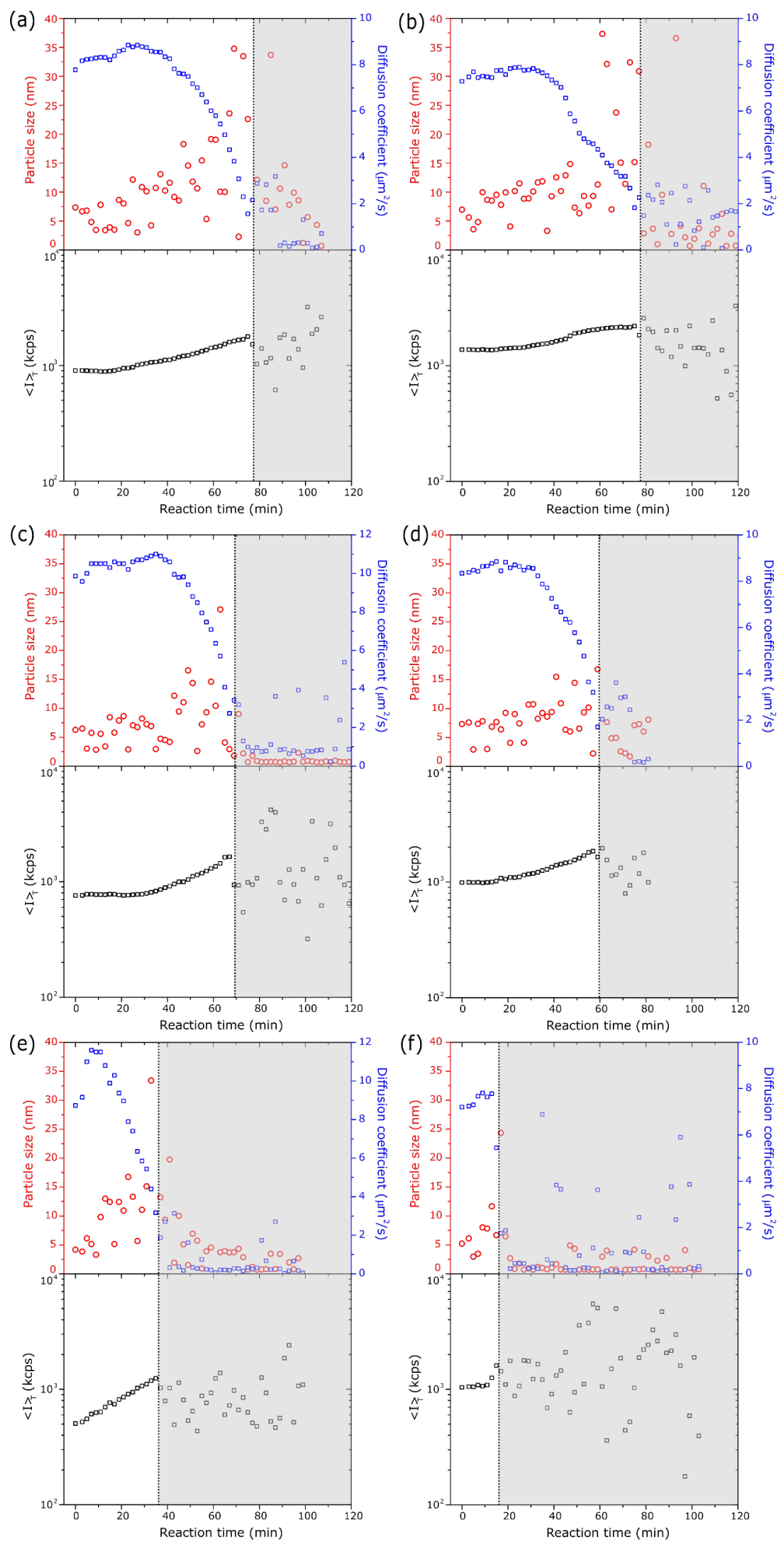

Figure S7. Evolution of the fast $\left(\tau_{f}\right)$ and slow $\left(\tau_{s}\right)$ relaxation time modes, obtained from the fitting of the ICF with equation 1 , as a function of the reaction time for $1.38 \mathrm{mM}$ of $\left(\mathbf{C}_{12} \text { RhMOP)(bix }\right)_{12}$ samples prepared with (a) 0.5 eq, (b) 1.0 eq., (c) 2.0 eq, (d) 6.0 eq., (e) 12.0 eq. and (f) 24.0 eq. of TFA. 


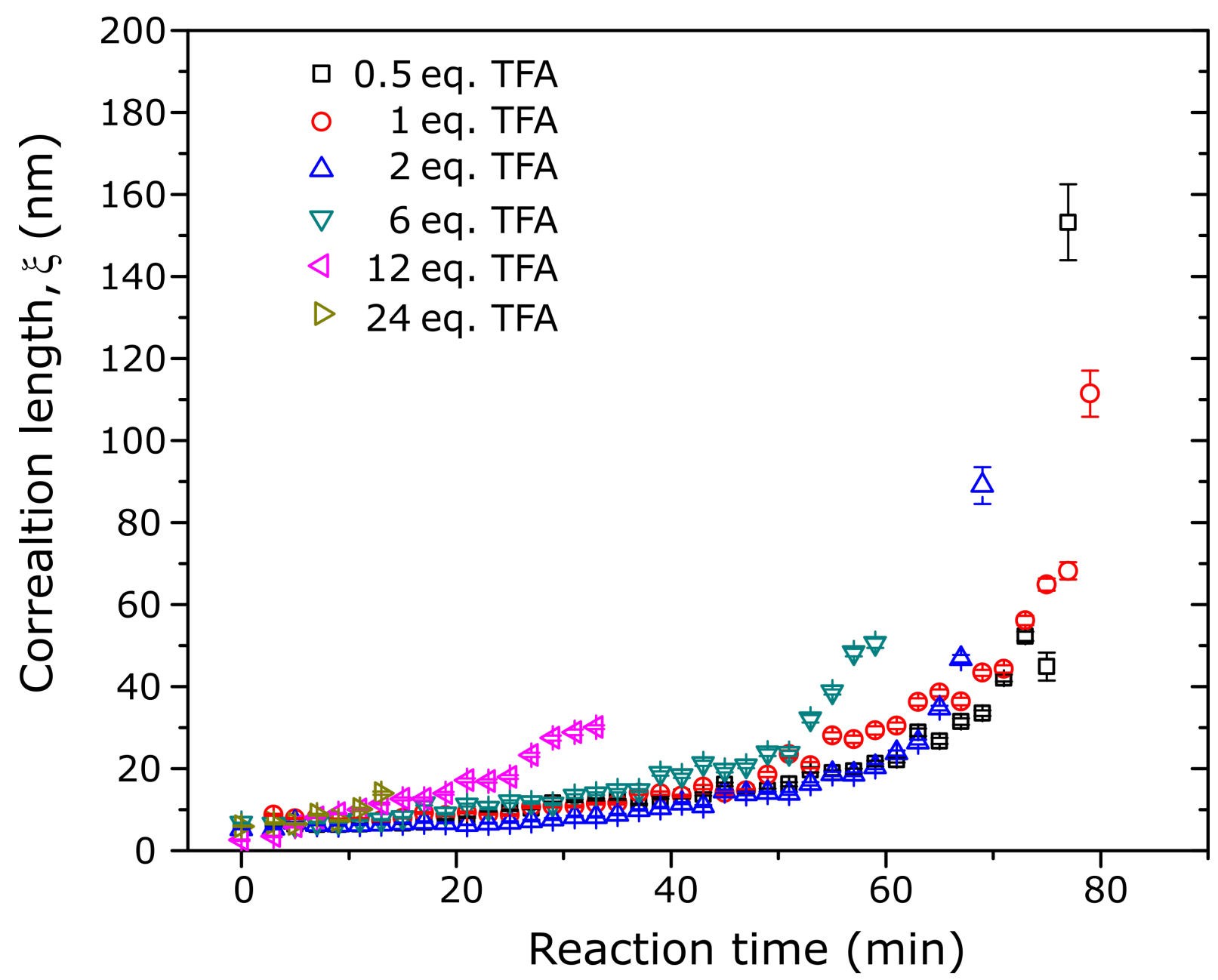

Figure S8. Variation of the correlation length of $1 \mathrm{a}-\mathrm{f}$ as a function of the reaction time for $1.38 \mathrm{mM}$ of ( C $_{12}$ RhMOP)(bix) $)_{12}$ samples prepared with (a) 0.5 eq, (b) 1.0 eq., (c) 2.0 eq, (d) 6.0 eq., (e) 12.0 eq. and (f) 24.0 eq. of TFA at room temperature. 

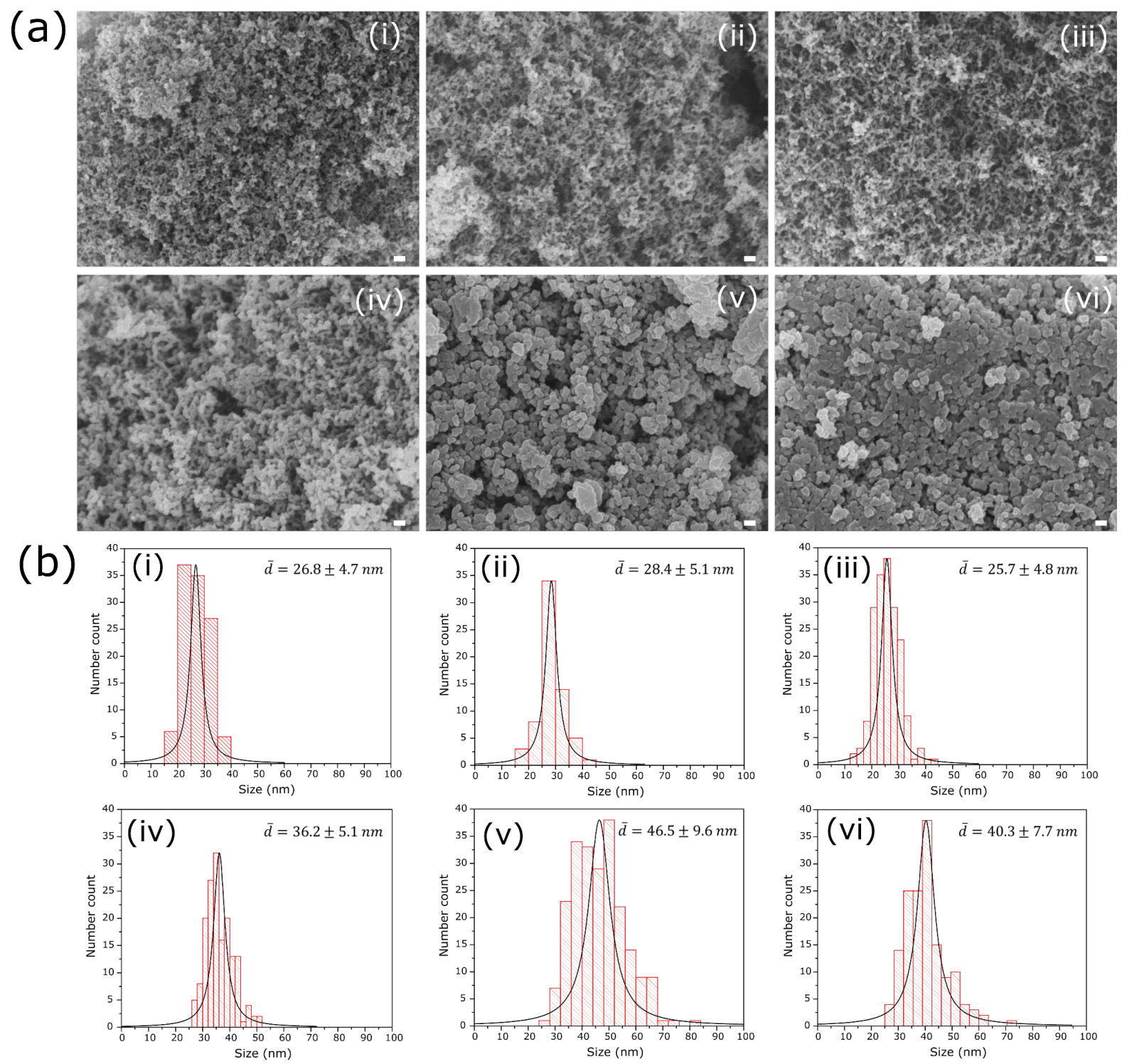

Figure S9. a) FE-SEM images and (b) the corresponding size distribution of colloid particles determined for the aerogel $2 a-f$ prepared with (i) 0.5 eq, (ii) 1.0 eq., (iii) 2.0 eq, (iv) 6.0 eq., (v) 12.0 eq. and (vi) 24.0 eq. of TFA. The scale bars are $100 \mathrm{~nm}$. The size distributions were obtained from the measurement of 150-160 particle sizes on at least three distinct FE-SEM images for each sample. 


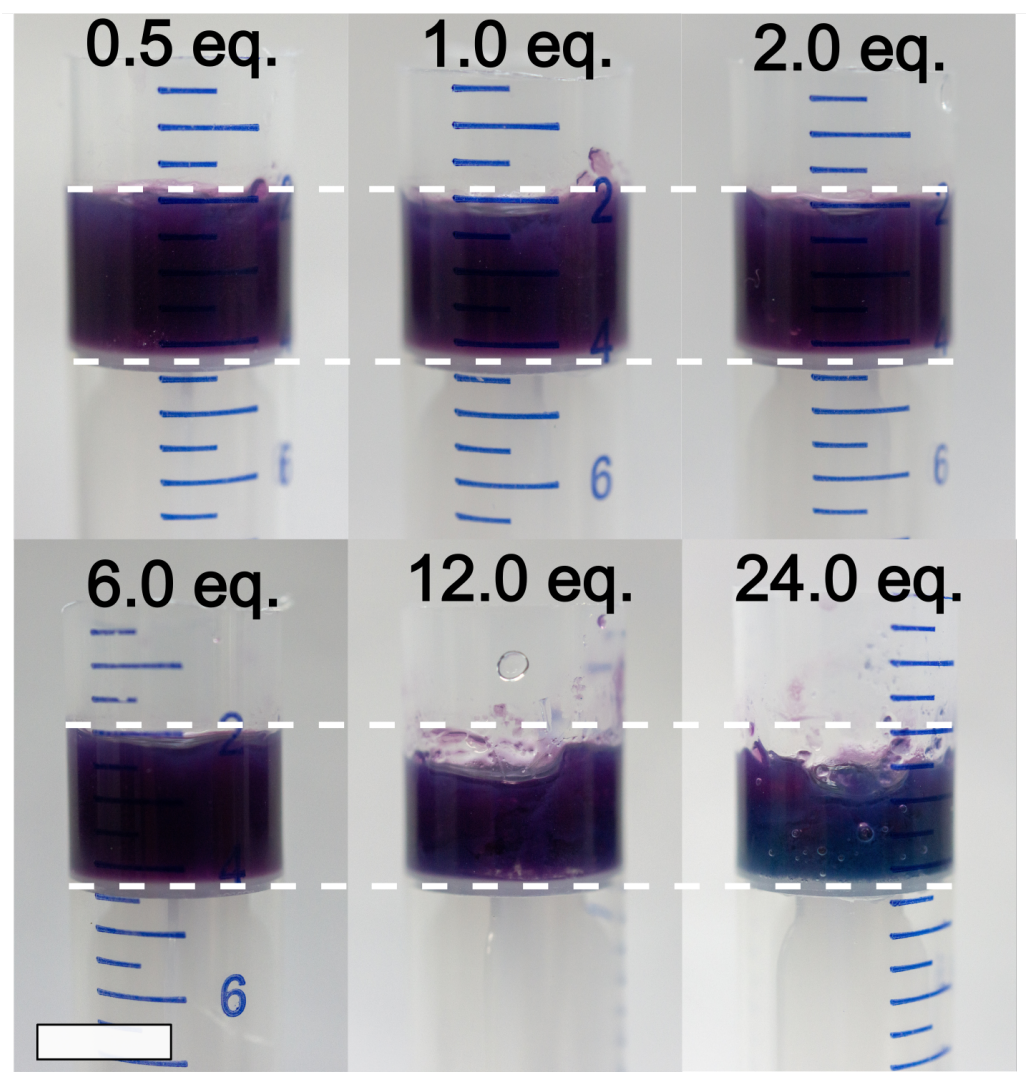

Figure S10. Photography of (a) the gels 1a-f prepared with different equivalent of TFA at room temperature showing the reduction of the gel volume at high TFA content as highlighted by the white dotted line. The scale bar is $1 \mathrm{~cm}$. 


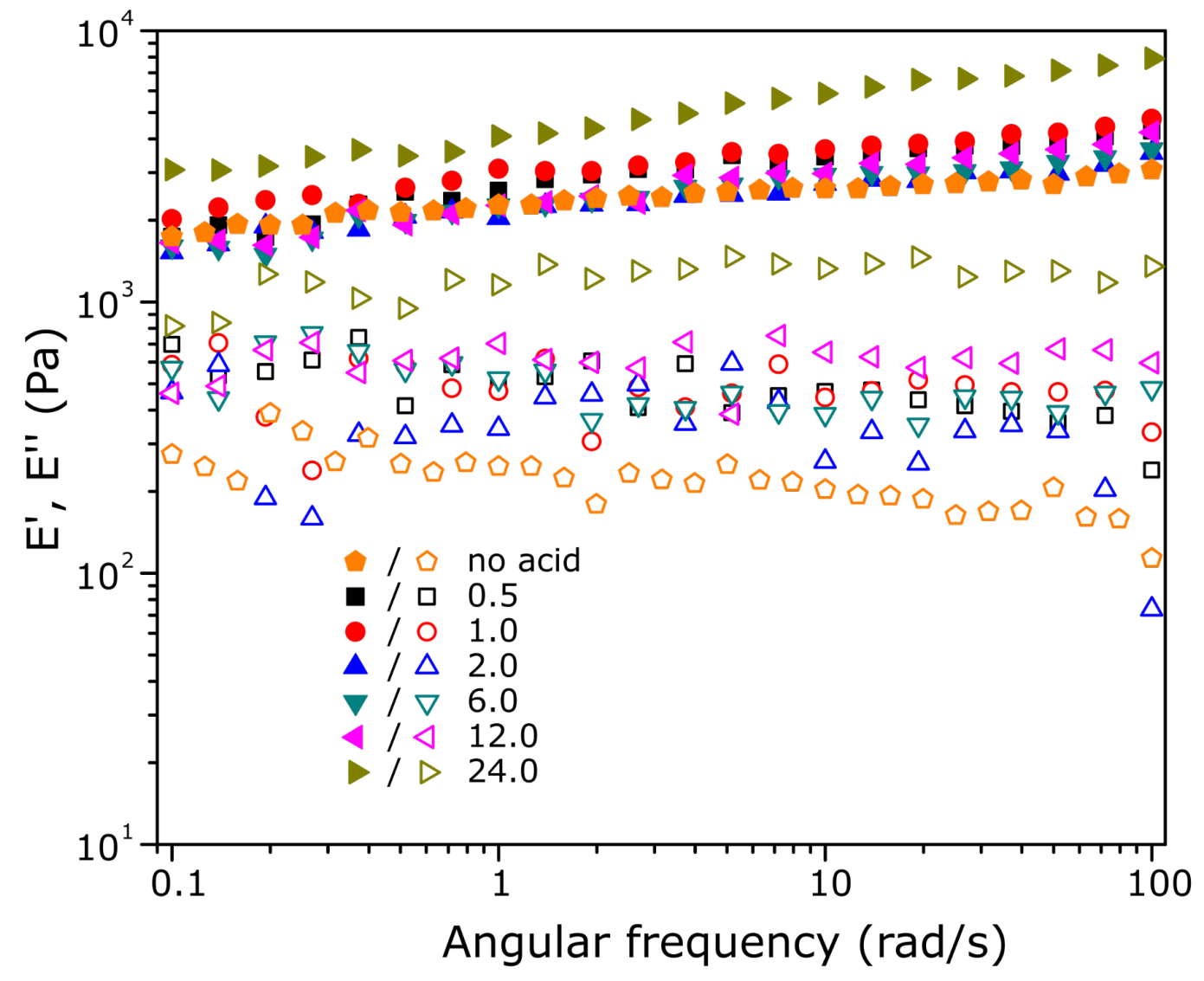

Figure S11. Storage and loss Young's modulus, E' and E', of the gel 1a-f and the gel prepared without acid as a function of the oscillatory deformation frequency $\omega$, at a fixed strain amplitude (1\%) within the linear viscoelastic regime. 


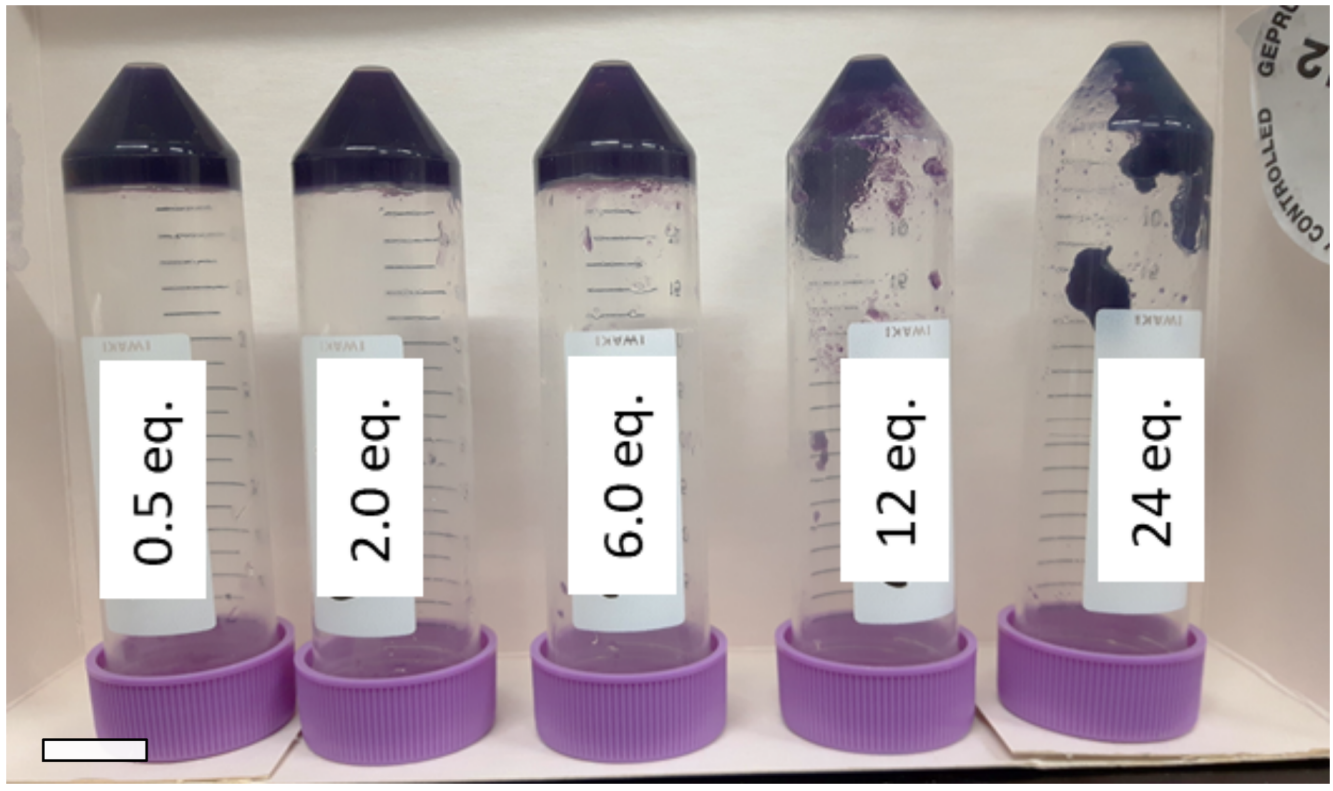

Figure S12. Photography demonstrating, with the inverted test, the gel state of the samples 1a-f prepared with different molar equivalents of TFA. Gels $1 \mathbf{e}$ and $\mathbf{1 f}$ appear to be more brittle than the one prepared with lower TFA concentration. The scale bar is $2 \mathrm{~cm}$. 

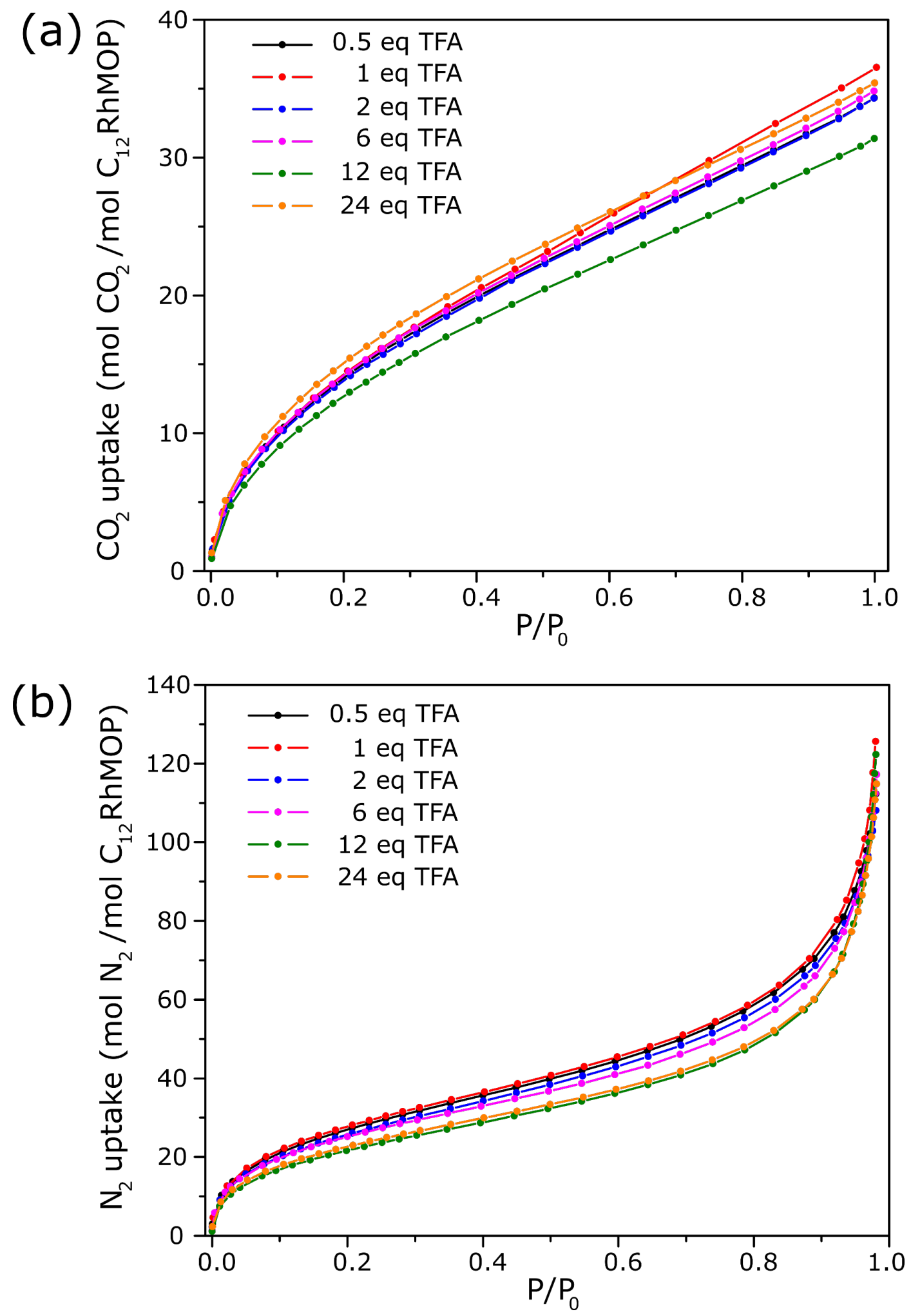

Figure S13. (a) $\mathrm{N}_{2}$ uptake (77 K) and (b) $\mathrm{CO}_{2}$ uptake (195 K) for aerogel samples 2a-f prepared with different molar equivalents of TFA. 

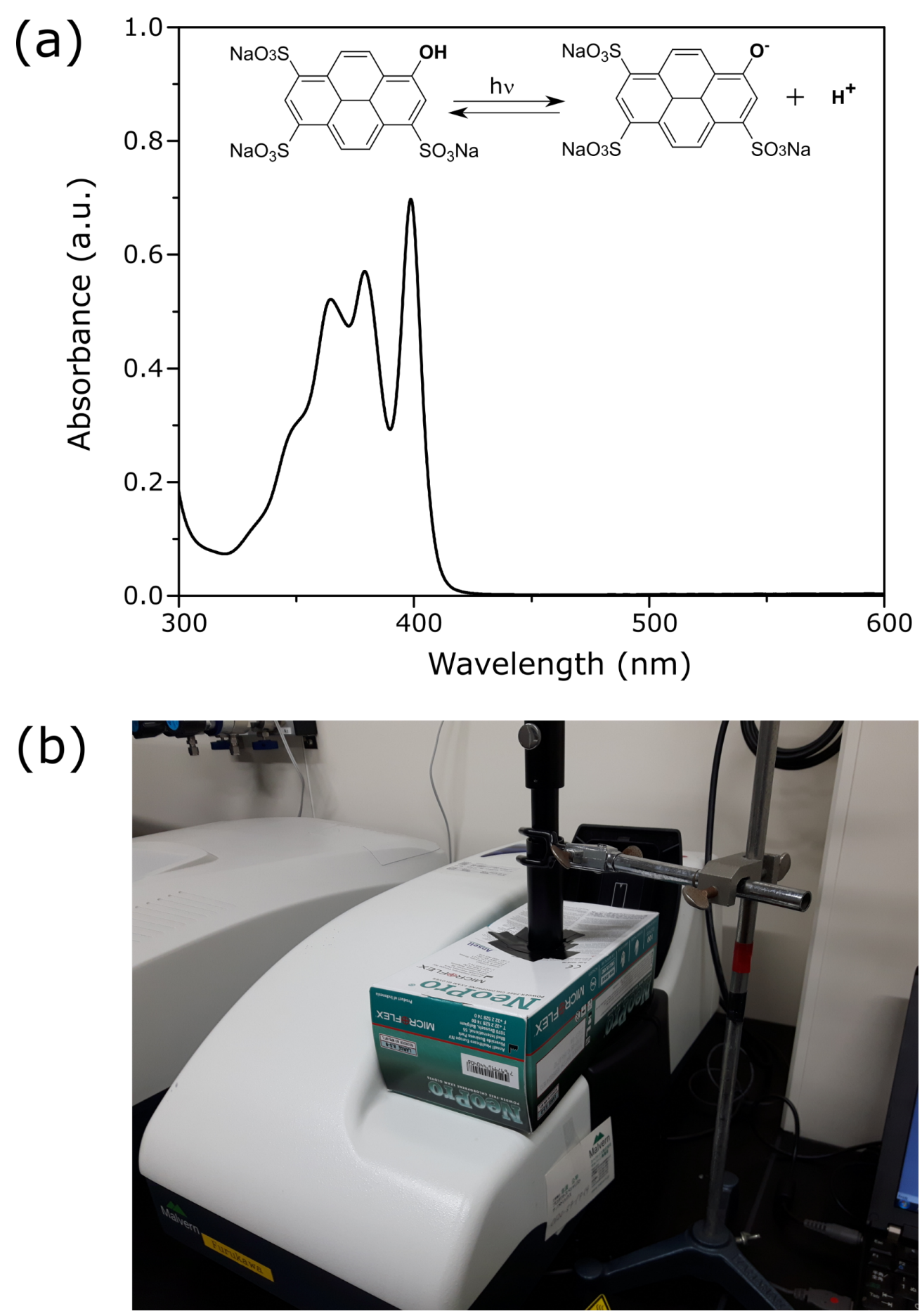

Figure S14. a) Uv-visible absorption spectrum of pyranine. Insert showing the reaction of the dissociation of pyranine into a proton and formation of the conjugated photobase upon light irradiation in the UV region. b) Modified setup of the dynamic light scattering (DLS) machine in order to perform in situ light irradiation of the sample during time-resolved DLS measurement 

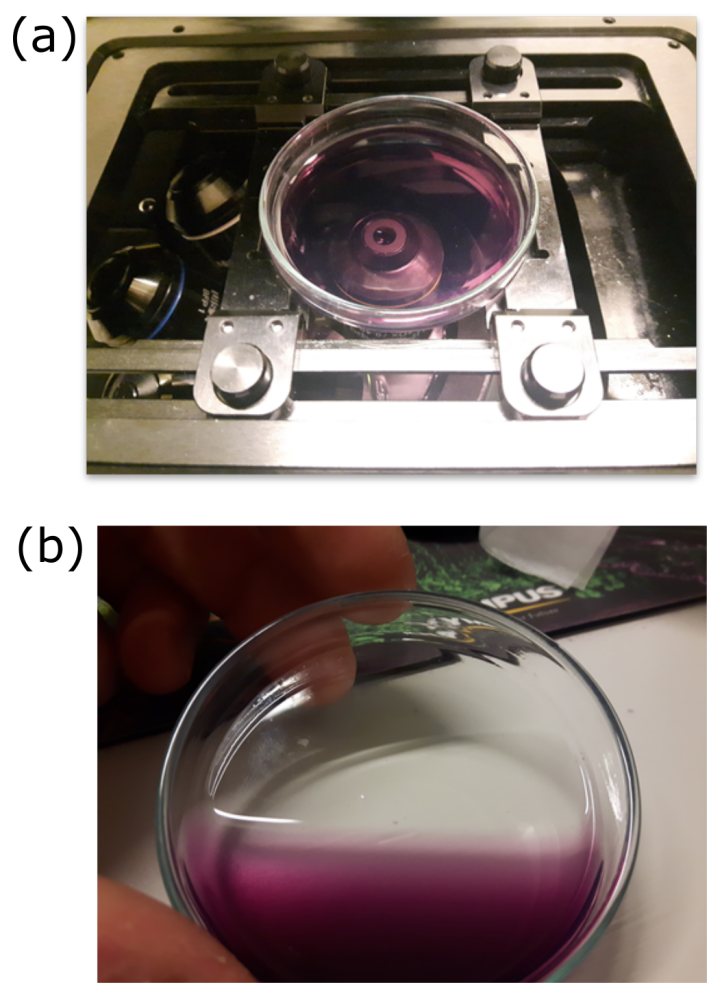

Figure S15. Photography showing the experimental setup of the confocal laser scanning microscope (CLSM) and a $1.1 \mathrm{mM}$ solution of the kinetically trapped phase $\left(\mathbf{C}_{12} \mathbf{R h M O P}\right)(\mathbf{b i x})_{12}$ without pyranine a) before and b) after irradiation for $30 \mathrm{~min}$ with a $405 \mathrm{~nm}$ laser. No gel was formed ruling out subsequent thermal effect. The petri dish has a diameter of $6 \mathrm{~cm}$.

1. Carné-Sánchez, A.; Craig, G. A.; Larpent, P.; Hirose, T.; Higuchi, M.; Kitagawa, S.; Matsuda, K.; Urayama, K.; Furukawa, S., Self-assembly of metal-organic polyhedra into supramolecular polymers with intrinsic microporosity. Nat. Commun. 2018, 9 (1), 2506.

2. Kawano, R.; Horike, N.; Hijikata, Y.; Kondo, M.; Carné-Sánchez, A.; Larpent, P.; Ikemura, S.; Osaki, T.; Kamiya, K.; Kitagawa, S.; Takeuchi, S.; Furukawa, S., Metal-Organic Cuboctahedra for Synthetic Ion Channels with Multiple Conductance States. Chem 2017, 2 (3), 393-403.

3. Furukawa, S.; Horike, N.; Kondo, M.; Hijikata, Y.; Carné-Sánchez, A.; Larpent, P.; Louvain, N.; Diring, S.; Sato, H.; Matsuda, R.; Kawano, R.; Kitagawa, S., Rhodium-Organic Cuboctahedra as Porous Solids with Strong Binding Sites. Inorg. Chem. 2016, 55 (21), 10843-10846.

4. $\quad$ Mitsuhiro, S.; Tomohisa, N., Gel Formation Analyses by Dynamic Light Scattering. Bull. Chem. Soc. Jpn. 2002, 75 (4), 641-659.

5. $\quad$ Hule, R. A.; Nagarkar, R. P.; Altunbas, A.; Ramay, H. R.; Branco, M. C.; Schneider, J. P.; Pochan, D. J., Correlations between structure, material properties and bioproperties in selfassembled $\beta$-hairpin peptide hydrogels. Faraday Discuss. 2008, 139 (0), 251-264.

6. Kureha, T.; Minato, H.; Suzuki, D.; Urayama, K.; Shibayama, M., Concentration dependence of the dynamics of microgel suspensions investigated by dynamic light scattering. Soft Matter 2019, 15 (27), 5390-5399. 